\title{
N-Cadherin Sustains Motility and Polarity of Future Cortical Interneurons during Tangential Migration
}

\author{
Camilla Luccardini, ${ }^{1,2}$ Laetitia Hennekinne, ${ }^{1,2}$ Lucie Viou, ${ }^{1,2}$ Mitsutoshi Yanagida, ${ }^{3}$ Fujio Murakami, ${ }^{3}$ \\ Nicoletta Kessaris, ${ }^{4}$ Xufei Ma, ${ }^{5}$ Robert S. Adelstein, ${ }^{5}$ René-Marc Mège, ${ }^{1,2}$ and Christine Métin ${ }^{1,2}$ \\ ${ }^{1}$ Institut National de la Santé et de la Recherche Médicale, Unité Mixte de Recherche 839, Institut du Fer à Moulin, 75005 Paris, France, ${ }^{2}$ Université Pierre et \\ Marie Curie-Paris 6, 75005 Paris, France, ${ }^{3}$ Graduate School of Frontier Biosciences, Osaka University, Osaka 565-0871, Japan, ${ }^{4}$ Wolfson Institute for \\ Biomedical Research and Department of Cell and Developmental Biology, University College London, London, WC1E 6BT, United Kingdom, and \\ ${ }^{5}$ Laboratory of Molecular Cardiology, National Heart, Lung, and Blood Institute, National Institutes of Health, Bethesda, Maryland 20892
}

In the developing brain, cortical GABAergic interneurons migrate long distances from the medial ganglionic eminence (MGE) in which they are generated, to the cortex in which they settle. MGE cells express the cell adhesion molecule N-cadherin, a homophilic cell-cell adhesion molecule that regulates numerous steps of brain development, from neuroepithelium morphogenesis to synapse formation. $\mathrm{N}$-cadherin is also expressed in embryonic territories crossed by MGE cells during their migration. In this study, we demonstrate that $\mathrm{N}$-cadherin is a key player in the long-distance migration of future cortical interneurons. Using N-cadherin-coated substrate, we show that N-cadherin-dependent adhesion promotes the migration of mouse MGE cells in vitro. Conversely, mouse MGE cells electroporated with a construct interfering with cadherin function show reduced cell motility, leading process instability, and impaired polarization associated with abnormal myosin IIB dynamics. In vivo, the capability of electroporated MGE cells to invade the developing cortical plate is altered. Using genetic ablation of $\mathrm{N}$-cadherin in mouse embryos, we show that $\mathrm{N}$-cadherin-depleted MGEs are severely disorganized. MGE cells hardly exit the disorganized proliferative area. $\mathrm{N}$-cadherin ablation at the postmitotic stage, which does not affect MGE morphogenesis, alters MGE cell motility and directionality. The tangential migration to the cortex of $N$-cadherin ablated MGE cells is delayed, and their radial migration within the cortical plate is perturbed. Altogether, these results identify $\mathrm{N}$-cadherin as a pivotal adhesion substrate that activates cell motility in future cortical interneurons and maintains cell polarity over their long-distance migration to the developing cortex.

\section{Introduction}

$\mathrm{N}$-cadherin (N-cad or cad 2) is a homophilic cell adhesion molecule expressed widely in the developing CNS starting at neurulation (Hatta and Takeichi, 1986; Miyatani et al., 1989; Redies and Takeichi, 1996). N-cadherin plays a crucial role in controlling the polarized organization of proliferative neuroepithelia (Gänzler-Odenthal and Redies, 1998; Junghans et al., 2005; Lien et al., 2006; Kadowaki et al., 2007). At later developmental stages, $\mathrm{N}$-cadherin both mediates selective adhesiveness between neural cells and induces axonal out-

Received Feb. 7, 2013; revised 0ct. 4, 2013; accepted 0ct. 8, 2013.

Author contributions: C.M. designed research; C.L., L.H., L.V., and M.Y. performed research; F.M., N.K., X.M., R.S.A., and R.-M.M. contributed unpublished reagents/analytic tools; C.L., L.H., and C.M. analyzed data; C.L., R.-M.M., and C.M. wrote the paper.

This work was supported by Institut National de la Santé et de la Recherche Médicale (INSERM), Agence Nationale pour la Recherche (ANR Grant MRGENE), Japan Society for the Promotion of Science (JSPS), Fondation J. Lejeune and Fondation pour la Recherche sur le Cerveau, Association pour la Recherche sur le Cancer, and I'Association Française Contre les Myopathies. C.L. was supported by a grant from Neuropole lle de France and by the Grant MRGENE from ANR, L.V. by a Ministère de la Recherche et Technologie fellowship, and L.V. and M.Y. by an INSERM-JSPS travel grant. We thank V. Castellani, F. Francis, and P. Gaspar for reading and comments on this manuscript, K. Aubrey for English revision, F. Matsuzaki and M. Bornens for reagents, and Institut du Fer à Moulin Imaging Facility and Animal Facility.

The authors declare no competing financial interests.

Correspondence should be addressed to Christine Métin, Institut National de la Santé et de la Recherche Médicale, Unité 839, Institute of Ferà Moulin, 17, rue du Fer à Moulin, 750045 Paris, France. E-mail: christine.metin@inserm.fr. DOI:10.1523/JNEUROSCI.0593-13.2013

Copyright $\odot 2013$ the authors $\quad 0270-6474 / 13 / 3318149-12 \$ 15.00 / 0$ growth and growth cone migration (Matsunaga et al., 1988; Bixby and Zhang, 1990; Letourneau et al., 1990; Riehl et al., 1996; for review, see Hirano and Takeichi, 2012), likely by interacting with actin treadmilling (Mège et al., 2006; Bard et al., 2008).

$\mathrm{N}$-cadherin is expressed in the developing telencephalon along the migratory paths of the two main classes of cortical neurons: (1) the radially migrating glutamatergic neurons and (2) the tangentially migrating GABAergic interneurons (Redies and Takeichi, 1993; Kadowaki et al., 2007), suggesting its participation in cortical migrations. Recent data indeed show that the radial glia-dependent migration of glutamatergic cortical neurons requires the dynamic recycling of N-cadherin at their surface (Kawauchi et al., 2010). $\mathrm{N}$-cadherin is also needed for the glia-independent somal translocation of projection neurons toward the marginal zone (MZ) of the cortex and when cortical neurons switch from their multipolar state in the intermediate zone (IZ) to their radially polarized shape in the cortical plate (CP) (Franco et al., 2011; Jossin and Cooper, 2011; Gil-Sanz et al., 2013). In contrast, the role of $\mathrm{N}$-cadherin in the regulation of the migration of cortical inhibitory interneurons has not been investigated, although $\mathrm{N}$-cadherin is present along the entire migration path of cortical interneurons and has been shown to promote the long-distance migration of neurons in the hindbrain (Taniguchi et al., 2006).

GABAergic cortical interneurons are generated in the subpallium and migrate tangentially to the cortex going through the $\mathrm{MZ}$ 
or the IZ/subventricular zone (SVZ). In the cortical wall, they reorient their trajectory to enter the developing CP (Marín and Rubenstein, 2001). This long-distance journey depends on both diffusible and contact guidance cues (Marín et al., 2010). The importance of specific adhesive interactions with cellular substrates is emerging (for review, see Solecki, 2012).

Here we examined whether $\mathrm{N}$-cadherin-mediated homophilic adhesion controls the tangential migration of future cortical interneurons. Using N-cad-Fc biomimetic substrates (Lambert et al., 2000), we show that $\mathrm{N}$-cadherin engagement activated medial ganglionic eminence (MGE) cell migration in vitro by stimulating cell motility and leading process elongation. Conversely, MGE cells with inactivated cadherin exhibited slowed migration and polarity defects associated with abnormal actomyosin contractility. In utero electroporation of dominant-negative forms of $\mathrm{N}$-cadherin and genetic ablation of $\mathrm{N}$-cadherin in proliferative or postmitotic MGE cells further confirmed that $\mathrm{N}$-cadherin not only controls the exit of future cortical interneurons away from the neuroepithelium in the MGE but moreover promotes their directional migration to the embryonic cortex and, later, their radial migration in the developing $\mathrm{CP}$. These data identify $\mathrm{N}$-cadherin as a pivotal adhesion molecule in the long journey of migrating cortical interneurons.

\section{Materials and Methods}

Animals. Mice were housed and mated in a conventional animal facility according to European guidelines. In this study, we used mouse embryos of either sex produced by crossing adults from a loxP-flanked $\mathrm{N}$-cadherin line (Radice et al., 1997) with either Nkx 2.1-Cre, Rosa26R-GFP (Kessaris et al., 2006) or Lhx6-Cre, Rosa26R-GFP (Fogarty et al., 2007) transgenic mice. Midday of the day of vaginal plug formation was considered E0.5. Swiss mice (Janvier) were used for cocultures experiments and in utero electroporation. Embryos expressing ubiquitously the GFP-NMHC II-B (GFP-NMIIB) fusion protein resulted from crosses between mutant mice generated by homologous recombination to express the GFP-tagged fulllength coding region of human NMHC II-B (GFP-NMIIB) under the control of the endogenous NMHC II-B promoter (Bao et al., 2007).

Tissue preparation and coculture experiments. Embryonic brains were dissected in cold Leibovitz medium (Invitrogen) and immersion fixed in cold $4 \%(\mathrm{w} / \mathrm{v})$ paraformaldehyde in $0.12 \mathrm{~m}$ phosphate buffer, $\mathrm{pH} 7.4$, overnight. Brains were then embedded in $3 \%$ agarose and coronally sectioned with the vibratome at $50 \mu \mathrm{m}$. Cocultures were prepared as described previously (Bellion et al., 2005). N-cadherin substrates were prepared as detailed previously by Lambert et al. (2000). Briefly, glass coverslips were incubated overnight at $4^{\circ} \mathrm{C}$ with $3 \mu \mathrm{g} / \mathrm{ml}$ poly-ornithine (Sigma) and $4 \mu \mathrm{g} / \mathrm{ml}$ goat anti-human Fc antibody (Jackson ImmunoResearch). Coverslips were then washed and incubated with $1 \mu \mathrm{g} / \mathrm{cm}^{2} \mathrm{pu}-$ rified $\mathrm{N}$-cad-hFc chimera for $3 \mathrm{~h}$ at $37^{\circ} \mathrm{C}$. $\mathrm{N}$-cadherin/laminin-coated coverslips were prepared as above except for the addition of $4 \mu \mathrm{g} / \mathrm{ml}$ laminin (Sigma) to $4 \mu \mathrm{g} / \mathrm{ml}$ goat anti-human Fc antibody. Cocultures and cultures were fixed in $4 \%(\mathrm{w} / \mathrm{v})$ paraformaldehyde in $0.12 \mathrm{M}$ phosphate buffer, $\mathrm{pH} 7.4$, with $0.33 \mathrm{~m}$ sucrose for $3 \mathrm{~h}$. Cultures prepared for Golgi staining were fixed for $10 \mathrm{~min}$ in methanol at $-20^{\circ} \mathrm{C}$ and then rinsed in PBS.

In vitro electroporation. In vitro electroporation of MGE explants was performed as described by Baudoin et al. (2012). $p C A G-E G F P, p C A G-C r e$ and $p C A G-E G F P-N-c a d(t)$ constructs were used at a final concentration of 1 $\mu \mathrm{g} / \mu \mathrm{l}$, whereas $p C A G-R F P, p C A G-T o m a t o$ and $p-C A G-P A C T-m K O 1$ constructs were used at $0.5 \mu \mathrm{g} / \mu \mathrm{l}$.

In utero electroporation. Ganglionic eminence directed in utero electroporation was performed on E12.5 wild-type embryos of timed pregnant females as described previously (Tanaka et al., 2003). Glass capillaries (Narishige) were pulled and calibrated for 1-2 $\mu$ l plasmid injections. After DNA injection into the lateral ventricle, five pulses separated by $950 \mathrm{~ms}$ were applied at $60 \mathrm{~V}$ for $50 \mathrm{~ms}$ at an angle of $30-60^{\circ}$ from the horizontal plane (electrodes LF650P2; BEX). pCAG-EGFP, $p C A G-E G F P-N-c a d(t)$ and $p C A G-c N 390 \Delta$ constructs (Taniguchi et al., 2006) were diluted in PBS and $0.01 \%$ fast green at a final concentration
$2.5 \mu \mathrm{g} / \mu$ l. Embryos were allowed to develop in utero for $3 \mathrm{~d}$ and killed at E15.5.

Immunohistochemistry. Brain sections and fixed neurons were permeabilized in $0.25 \%(\mathrm{w} / \mathrm{v})$ Triton X-100 and then blocked for $2 \mathrm{~h}$ with $2 \mathrm{~g} / \mathrm{L}$ gelatin and $2 \%$ normal goat serum, respectively. The following primary antibodies were used: chicken anti-GFP (1:5000; Aves Labs), rabbit antiGFP (1:1000; Invitrogen), rabbit anti-N-cadherin (1:100; Santa Cruz Biotechnology), rabbit anti- $\beta$-catenin (1:500; Sigma), anti-phosphohistone 3 (1:500; Millipore), mouse anti-TUJ1 (1:500; Babco), mouse IgM anti-RC2 (1:20; Developmental Studies Hybridoma Bank) and antibodies against Golgi proteins [mouse IgG clone CTR433 at 1:100 on methanol-fixed cultures (generous gift from Michel Bornens, Institut Curie/CNRS UMR 144, Paris, France) or rabbit anti-GM130 at 1:100 on paraformaldehyde-fixed sections (Sigma)]. Appropriate Alexa Fluor dye-conjugated secondary antibodies (1:500; Invitrogen) were used to detect primary antibodies. Brain sections were extensively washed in PBS after antibody incubation. DAPI (1:5000; Sigma) was used for fluorescent nuclear counterstaining. Slices and cocultures were mounted in Mowiol-Dabco and observed with either an epifluorescence macroscope (MVX10; Olympus) or an upright fluorescence microscope (DM6000; Leica). Cell counting and immunofluorescence analysis in brain sections were performed on a series of confocal sections acquired using a confocal microscope (TCS SP5 II; Leica) or a spinning-disk confocal microscope (DMI4000; Leica). Image reconstruction of the whole embryonic cortex was performed using the automatic "stitching" function of the Leica TCS SP5 II confocal microscope or using the "stack combine" function of NIH ImageJ.

Live-cell imaging. Time-lapse imaging was performed with either an inverted wide-field fluorescent microscope or an inverted spinning-disk confocal microscope (DMI4000; Leica) equipped with a temperaturecontrolled chamber. Cocultures were imaged with a $20 \times$ or $40 \times$ objective. Stacks were captured with a Coolsnap HQ camera (Roper Scientific) every 3 or $5 \mathrm{~min}$ for up to $10 \mathrm{~h}$. Control and mutant MGE cells were recorded at the same time under the same acquisition conditions. Pictures were acquired using MetaMorph software, and cell tracking was performed with either MetaMorph or NIH ImageJ software (MTrackJ).

Cell counting and measurement. Cell counting in a volume or surface, migration area measurement around MGE explants, measurement of leading process length, and cell migration speed in time-lapse experiments were performed with either MetaMorph or NIH ImageJ software, especially with Cell Counter, MTrackJ, and NeuronJ plugins.

Statistical analyses. Statistical analyses made use of Student's $t$ and $\chi^{2}$ tests or Mann-Whitney test for nonparametric samples, across $n$ samples, where $n$ is the number of embryos or cells as specified in the figure legends.

\section{Results}

$\mathrm{N}$-cadherin promotes motility of migrating MGE cells in vitro

To test whether N-cadherin is a potent substrate for MGE cell migration, we compared the migration of control MGE cells out of explants collected at E13.5 and cultured on a N-cadherin biomimetic substrate (Fig. 1B; Lambert et al., 2000) or on dissociated cortical cells, a well known substrate for MGE cell migration in vitro (Fig. 1A; Bellion et al., 2005). The $\mathrm{N}$-cadherin substrate provides a means to analyze the response of MGE cells to the selective stimulation of their $\mathrm{N}$-cadherin receptors.

MGE cells started migrating $\sim 18 \mathrm{~h}$ after MGE explant placement on cortical cells. As described previously (Bellion et al., 2005), nuclear movements were saltatory. Dynamic forward translocations of the nucleus directed toward a swelling in the leading neurite alternated with long nuclear resting phases during which the swelling widened (Fig. $1 A$, white arrowhead). Surprisingly, MGE cells started migrating several hours earlier on recombinant $\mathrm{N}$-cadherin than on dissociated cortical cells. The first migrating MGE cells were generally observed 4-6 h after MGE explant placement on recombinant N-cadherin. Analysis of nuclear dynamics showed that MGE cells migrated significantly 
Time lapse sequences

A Cortical cell substrate (CTL)

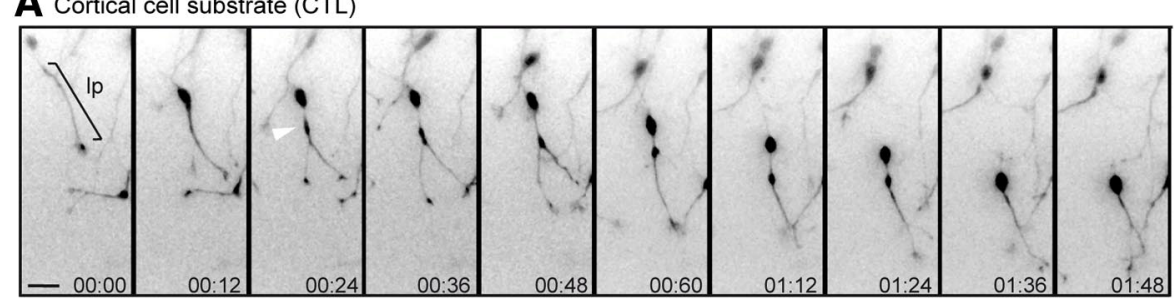

B N-cadherin coating ( $\mathrm{N}$-cad)

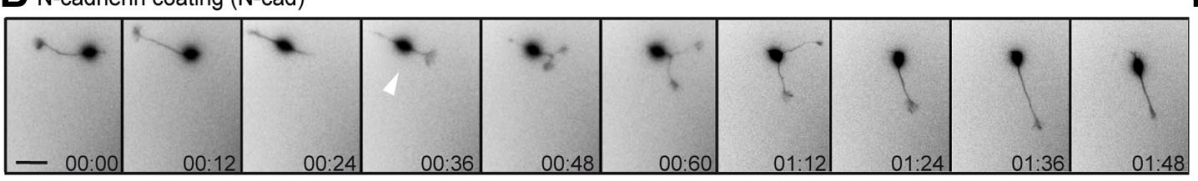

C N-cadherin/laminin coating (N-cad/LN)

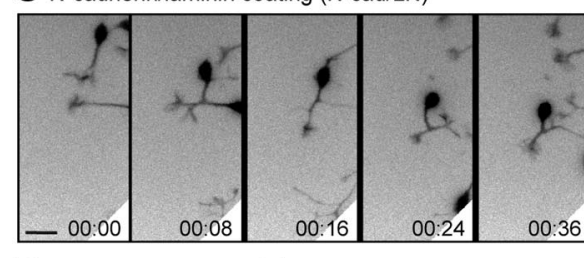

D Nuclear migration speed

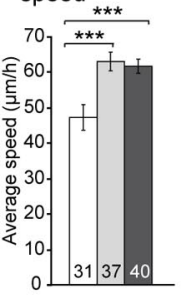

E Direction persistence $\mathrm{D} / \mathrm{T}$

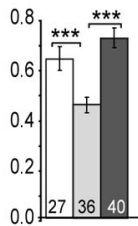

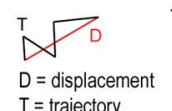

$T=$ trajectory

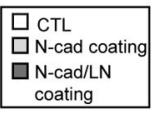

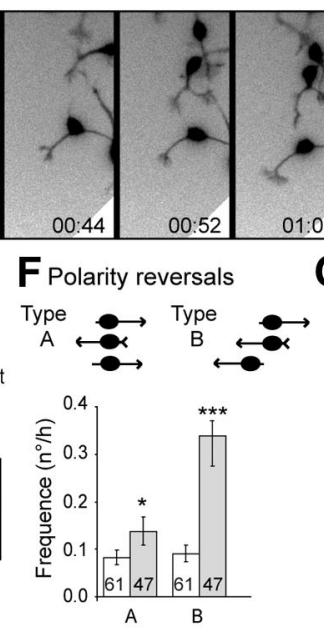

MGE cells trajectories

$\mathbf{A}^{\prime}$

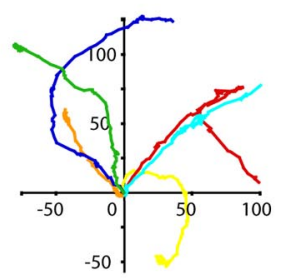

B'
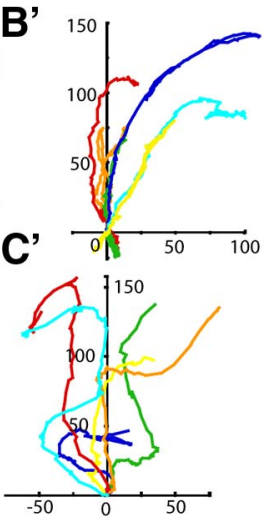

G Golgi apparatus (GA) positioning
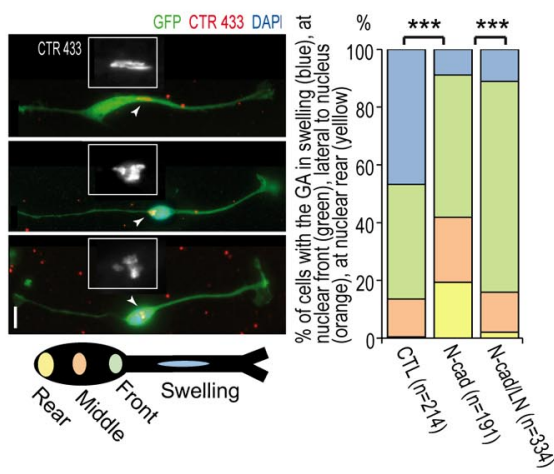

Figure 1. $\quad \mathrm{N}$-cadherin is a permissive substrate for MGE cell migration in vitro. $A-C$, Time-lapse sequences show the migration of wild-type MGE cells expressing GFP (inverted LUT) on dissociated cortical cells $(\boldsymbol{A}, \mathrm{CTL})$, on a biomimetic $\mathrm{N}$-cadherin substrate $(\boldsymbol{B}, \mathrm{N}$-cad), and on a substrate of $\mathrm{N}$-cadherin and laminin $(\boldsymbol{C}, \mathrm{N}$-cad/LN). Time is indicated in hours:minutes on frames. White arrowhead shows a swelling $(\boldsymbol{A})$ and a change in polarity $(\boldsymbol{B})$. Graphs in $\boldsymbol{A}^{\prime}-\boldsymbol{C}^{\prime}$ are characteristic examples of MGE cell trajectories on dissociated cortical cells $\left(\boldsymbol{A}^{\prime}\right), N$-cad coating $\left(\boldsymbol{B}^{\prime}\right)$, and N-cad/LN coating $\left(\boldsymbol{C}^{\prime}\right)$. $\boldsymbol{D}-\boldsymbol{F}$, MGE cells cultured on N-cad migrate faster than on dissociated cortical cells $(\boldsymbol{D})$. On N-cad coating, the direction persistence decreases but is rescued by laminin addition (E). On N-cad, the frequency of polarity reversals significantly increases compared with control $(\boldsymbol{F})$. G, Photomicrographs illustrate three migrating MGE cells on N-cad coating showing different subcellular localization of the Golgi apparatus (GA) revealed with CTR433 antibodies: top, at nuclear front; middle, at nuclear rear; bottom, in the middle of the nucleus. Histogram shows that MGE cells migrating on dissociated cortical cells (left bar, CTL) have a Golgi apparatus frequently located in a swelling of the leading process, whereas MGE cells migrating on N-cad (middle bar) have a Golgi apparatus more frequently found at the rear of the nucleus. Laminin addition to $\mathrm{N}$-cad (right bar) partially corrects the positioning of the Golgi apparatus. Numbers below the bars indicate the number of cells analyzed in each condition $\left({ }^{* * *} p<0.001, \chi^{2}\right.$ test). Ip, Leading process. Histograms $\boldsymbol{D}-\boldsymbol{F}$ show mean \pm SEM. Student's $t$ test, ${ }^{*} p<0.05,{ }^{* * *} p<0.001$. Scale bars: $\boldsymbol{A}-\boldsymbol{C}, 10 \mu \mathrm{m} ; \boldsymbol{G}, 5 \mu \mathrm{m}$.

faster on $\mathrm{N}$-cadherin substrate than on cortical cells (Fig. 1D), indicating that $\mathrm{N}$-cadherin engagement by itself is able to stimulate MGE cell motility, comprising nucleokinesis. On N-cadherin substrate, MGE cells did not form a cytoplasmic swelling and lost their typical saltatory behavior (Fig. 1B). Nevertheless, the overall efficacy of the migration was decreased because cells took meandering trajectories and underwent polarity reversals at much higher frequencies than on a substrate of cortical cells (Fig. $\left.1 A^{\prime}, B^{\prime}, E, F\right)$. We examined the polarity of MGE cells migrating on $\mathrm{N}$-cadherin by localizing the Golgi apparatus that tightly associates with the centrosome and can be used as a marker of cell polarity in migrating neurons (Bellion et al., 2005; Causeret et al., 2009; Jossin and Cooper, 2011; Yanagida et al., 2012). Immunostaining of the median Golgi with CTR433 antibodies (Fig. 1G) revealed that the Golgi was located in the swelling of the leading process or ahead of the nucleus in the vast majority of control
MGE cells. In contrast, the Golgi apparatus of MGE cells migrating on recombinant $\mathrm{N}$-cadherin was found frequently in the middle of the cell soma or at the rear of the nucleus and rarely in the leading process (histogram in Fig. $1 G$ ). Interestingly, among the different adhesion molecules that we tested (Cad-11, Cad-6, E-cad, and laminin), N-cadherin was the only substrate to efficiently stimulate the migration of MGE cells. N-cadherin stimulated motility but did not promote the sustained directional migration observed on cortical neurons. We thus tested whether concomitant activation of integrin-dependent cell adhesion would restore the directed migration observed on cortical cells. Addition of laminin to the $\mathrm{N}$-cadherin substrate rescued the migration efficacy defect seen on $\mathrm{N}$-cadherin but did not restore the saltatory progression of MGE cells (Fig. $1 C, C^{\prime}$ ). It did maintain the increased nuclear speed observed on $\mathrm{N}$-cadherin substrate alone (Fig. 1D) but diminished the frequency of polarity reversals 
(Fig. 1E). Accordingly, the abnormal localization of the Golgi observed on $\mathrm{N}$-cadherin-only substrate was partially but significantly rescued on the $\mathrm{N}$-cadherin/laminin substrate (Fig. 1G).

Altogether, these data suggest that $\mathrm{N}$-cadherin engagement stimulates MGE cell motility but cannot provide polarity cues when presented as a homogeneous substrate.

\section{Cadherin inactivation impairs cell motility, cell polarity, and cortical distribution of MGE cells}

To interfere with cadherin function, MGE cells were electroporated with the dominant-negative EGFP-N-cad $(t)$ construct (Fig. 2 ) that acts by sequestering endogenous catenins and perturbs signaling downstream classical cadherins (Taniguchi et al., 2006). In cocultures on cortical cells, the migration speed of MGE cells with inactivated cadherin was reduced by $58 \%$ on average $(n=15$ cells in each condition, $p<0.001$, Mann-Whitney test), and the frequency of polarity reversals was increased by sixfold. Polarity defects were confirmed by an analysis of the centrosome dynamics (Fig. $2 A, A^{\prime}$ ). In control cells, the centrosome spent most of its time ahead of the nucleus and in the swelling (Fig. 2B, white bars). In contrast, in MGE cells with inactivated cadherin, the centrosome was mislocated, spending equal time between the front and the rear of the nucleus (Fig. 2B, black bars).

The actomyosin cytoskeleton and cadherins are functionally linked (Giannone et al., 2009), and nucleokinesis in migrating neurons is controlled by actomyosin contractility (Bellion et al., 2005; Schaar and McConnell, 2005; Tsai et al., 2007; Martini and Valdeolmillos, 2010). We hypothesized that perturbation of $\mathrm{N}$-cadherin-mediated cell adhesion might affect cellular migration by altering the actomyosin cytoskeleton. To visualize myosin dynamics in control and cadherin-inactivated MGE cells, we monitored MGE cells from mice expressing a fusion protein, GFP-NMIIB (Bao et al., 2007). In control cells, NMIIB distributed in the whole cell body during nuclear resting phases and became asymmetrically distributed during nucleokinesis. It concentrated at the rear of the nucleus in a cuplike structure before and during the nuclear translocation and was maintained in the trailing process after nucleokinesis (Fig. 2C,D). These accumulations likely reflect cyclic local activation of the actomyosin cytoskeleton. In contrast, in MGE cells with inactivated cadherin, NMIIB did not stabilize at one pole of the nuclear compartment and rarely built cuplike structures at the rear of the nucleus (Fig. $\left.2 C^{\prime}, D\right)$. These results indicate that cadherin-dependent adhesion is critical for polarization of myosin IIB activity during nuclear translocation.

To further confirm that cadherin inactivation interfered with the migratory response activated by $\mathrm{N}$-cadherin receptor engagement, we cultured wild-type MGE explants electroporated with the dominant-negative EGFP-N-cad $(t)$ construct on an N-cadherin substrate. Postmitotic neurons with inactivated cadherin left MGE explants less efficiently than control neurons (Fig. $2 F, F^{\prime}$ ). The small number still able to migrate on the $\mathrm{N}$-cadherin substrate colonized twice smaller areas around MGE explants than control neurons (Fig. $2 \mathrm{H})$. Accordingly, leading processes of neurons with inactivated cadherin were clearly shorter than those of control cells (Fig. $\left.2 G, G^{\prime}, I\right)$. Together, these data indicate that loss of cadherin function in MGE cells prevents their exit from MGE explant in vitro and perturbs their migration by impairing cell polarity and leading process elongation and/or stability.

We then examined how cadherin inactivation alters the migration of MGE cells in vivo. We locally inhibited cadherin function in a fraction of early-born MGE cells by electroporating wild-type embryonic MGEs in utero at E12.5 with vectors ex- pressing either the cytoplasmic dominant-negative form of $\mathrm{N}$-cadherin [EGFP-N-cad $(t)]$ or a membrane-bound dominantnegative construct (cN390 $\Delta$; Taniguchi et al., 2006; Fig. 3 ) that should both sequester endogenous catenins and perturb signaling downstream classical cadherins. The distribution of electroporated MGE cells was analyzed at E15.5. In spite of impairment of cadherin function by either constructs, MGE development appeared normal. Cells electroporated with a control plasmid expressing GFP only were found in the MZ, CP, and IZ/SVZ (Fig. $3 B, C)$. As expected, they distributed in the whole latero-dorsal extent of the cortex and in the hippocampus. During inhibition of cadherin function with either EGFP-N-cad (t) or $\mathrm{cN} 390 \Delta$ constructs, MGE-derived cells still distributed in the whole neocortex and hippocampus, but only a small fraction of them could enter the CP and the MZ. Most of them remained in the IZ and ventricular zone (VZ)/SVZ (Fig. $\left.3 B^{\prime}, C^{\prime}, D\right)$.

These results indicate that classical cadherins play an important role to control the long-distance migration of future cortical interneurons toward the developing CP.

\section{Genetic ablation of $N$-cadherin in the MGE impairs MGE morphogenesis and MGE cell distribution in vivo}

Our in vitro experiments illustrated in Figure 1 showed that $\mathrm{N}$-cadherin receptor engagement was particularly efficient to activate MGE cell motility. We thus examined the specific role of $\mathrm{N}$-cadherin in the long-distance migration of MGE cells in conditional knock-outs (cKOs). To generate mice with $N$-cadherin KO MGE cells, we crossed a $N$-cadherin floxed allele mouse line (Radice et al., 1997) to an Nkx2.1-Cre, Rosa26R-GFP line (Kessaris et al., 2006). In cKO embryos $N$-cadherin ${ }^{f l / f l} ; N k x 2.1-C r e$; Rosa26R-GFP (named below N-cad ${ }^{f l f l}, \mathrm{Nkx} 2.1-$ cre,GFP), the embryonic lethality caused by $N$-cadherin ablation was bypassed. $\mathrm{N}$-cadherin was deleted in MGE progenitors at midgestation. Inducible GFP expression was used to detect $N$-cadherin ablated cells. By immunostaining brain slices with anti $\mathrm{N}$-cadherin and $\beta$-catenin antibodies, we confirmed $N$-cadherin ablation in the GFPpositive $\left(\mathrm{GFP}^{+}\right)$MGEs of N-cad ${ }^{f l / f l}, \mathrm{Nkx} 2.1-\mathrm{cre}$,GFP cKOs (Fig. 4). We analyzed the distribution of $\mathrm{GFP}^{+}$cells in cortical brain sections of control (N-cad $\left.{ }^{f /+}, \mathrm{Nkx} 2.1-\mathrm{cre}, \mathrm{GFP}\right)$ and cKOs (N-cad ${ }^{f / /}$ $f l, \mathrm{Nkx} 2.1-\mathrm{cre}, \mathrm{GFP})$ embryos. At E14.5, which corresponds to a period of intense tangential migration of MGE cells, numerous GFP ${ }^{+}$ cells born in subpallial regions expressing Nkx2.1 (Kessaris et al., 2006) distributed in the cortical IZ/SVZ and MZ of control brains (Fig. $5 A, B$ ). In contrast, $N$-cadherin ablated $\mathrm{GFP}^{+}$cells remained in the MGE and in other subpallial regions, mainly the anterior entopeduncular area, preoptic area, and septum (Fig. 5 $A^{\prime}$ ). A few mutant cells were found beyond the ventricular angle in the IZ of the cortex (Fig. 5B') and in some cases in the MZ. Low numbers of $\mathrm{N}$-cadherin KO cells colonized the piriform cortex and the mantle zone of the lateral ganglionic eminence (LGE; Fig. 5 $A^{\prime}$ ). Later at E16.5, N-cadherin $\mathrm{KO} \mathrm{GFP}^{+}$cells were found farther in the dorsomedial cortex, although they were much less abundant in $\mathrm{CP}$ compared with $\mathrm{GFP}^{+}$control cells that colonized the entire CP (Fig. 5G- $H^{\prime}$ ), suggesting a delay in either migration and/or $\mathrm{CP}$ colonization.

The genetic ablation of $N$-cadherin in the GFP ${ }^{+} N k x$ 2.1expressing subpallial domain caused additional defects. First, $N$-cadherin cKO $\left(\mathrm{N}\right.$-cad $\left.{ }^{f l / f l}, \mathrm{Nkx} 2.1-\mathrm{cre}, \mathrm{GFP}\right)$ mice showed an increased size of the lateral ventricles and an abnormal positioning of the $\mathrm{GFP}^{+}$territory compared with control littermates (Figs. 4, 5A, $A^{\prime}, F$ ). Second, as reported previously after targeted $N$-cadherin ablation in the telencephalon (Kadowaki et al., 2007), we observed the disruption of neuroepithelial integrity likely re- 
A Cortical cells substrate
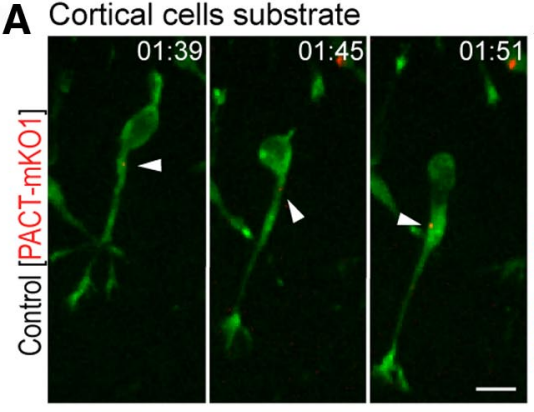

A'

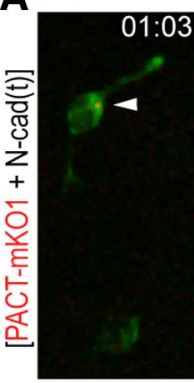

C Cortical cells substate
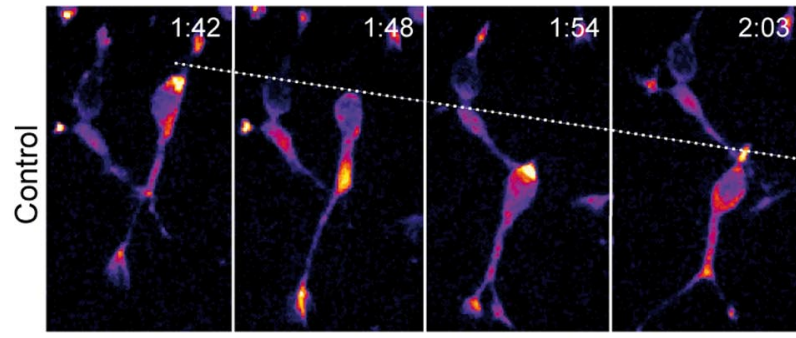

C' $1: 15$
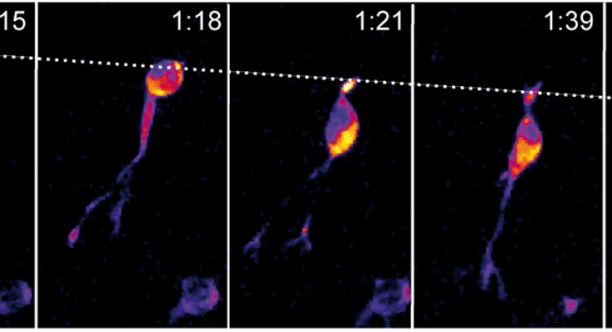

$1: 39$

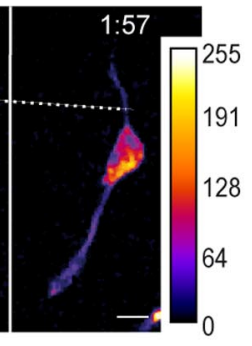

\section{$\mathrm{N}$-cadherin coating}

$\mathbf{F}$
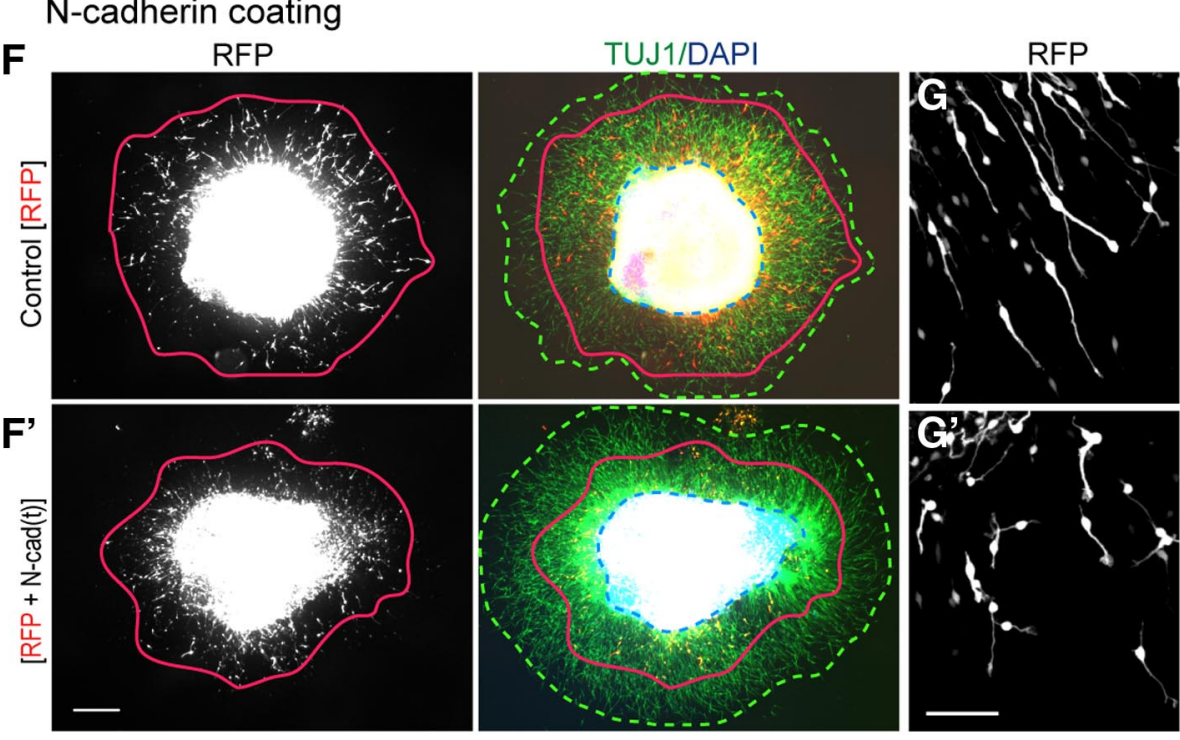

GFP-NMII

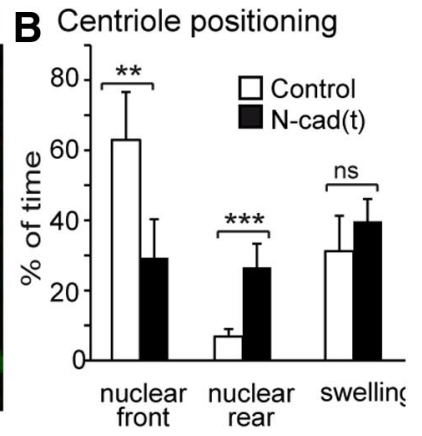

D Myosin IIB patterns

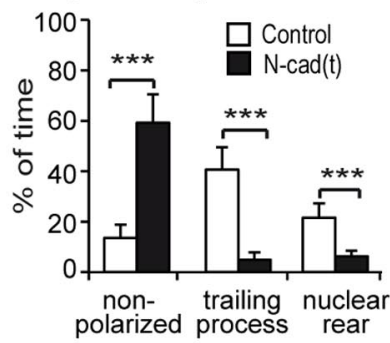

E Fluorescence intensity of GFP patterns

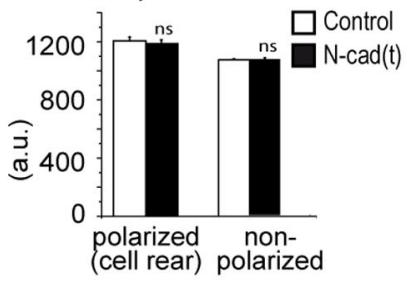

H Migration index of electroporated MGE cells

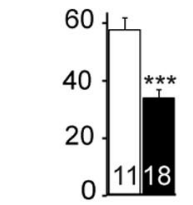

$\square$ CTL (RFP)

$\mathrm{N}-\operatorname{cad}(\mathrm{t})+\mathrm{RFP}$

I Mean length of

leading process

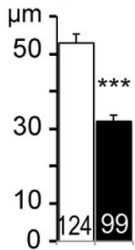

Figure 2. Cadherin inactivation with a cytoplasmic dominant negative construct alters the migration of MGE cells in vitro. $A, A^{\prime}$, Time-lapse sequences of cells from MGE explants dissected in GFP-NMIIB mice and electroporated with either the PACT-mKO1 $(\boldsymbol{A})$ or the PACT-mKO1 and dominant-negative EGFP-N-cad $(t)\left[\boldsymbol{A}^{\prime}, N\right.$-cad $\left.(\mathrm{t})\right]$ constructs. $\boldsymbol{B}$, Histogram shows that the centriole of control MGE cells spends most of its time ahead of the nucleus or in the swelling, whereas the centriole of MGE cells with inactivated cadherin spends equal time ahead and at the rear of the nucleus. $\mathbf{C} \boldsymbol{C}^{\prime}$, Time-lapse sequences of spatiotemporal pattern of GFP-NMIIB in control $(\boldsymbol{C})$ and cadherin inactivated $\left(\boldsymbol{C}^{\prime}\right)$ MGE cells. GFP-NMIIB is shown in pseudocolor. During nucleokinesis, NMIIB concentrates at the nuclear rear (D). This typical pattern is lost when cadherin function is inhibited $\left(\boldsymbol{C}^{\prime}, \boldsymbol{D}\right)$. $\boldsymbol{E}$, The expression of the EGFP-N-cad(t) construct in live MGE cells does not change the fluorescence intensity of GFP-NMIIB in neither polarized nor not polarized patterns of myosin. Time is in hours:minutes on frames. Histograms $\boldsymbol{B}, \boldsymbol{D}$, and $\boldsymbol{E}$ show mean \pm SEM (ns, not significant; one-way ANOVA test, $n=9$ for each condition). $\boldsymbol{F}-\boldsymbol{I}$, MGE explants electroporated with either an RFP construct $(\boldsymbol{F}, \boldsymbol{G})$ or the RFP and dominant-negative $E G F P-N$-cad $(t)$ constructs $\left(\boldsymbol{F}^{\prime}, \mathbf{G}^{\prime}\right)$ were cultured on a N-cadherin substrate for $36 \mathrm{~h}$. In $\boldsymbol{F}$ and $\boldsymbol{F}^{\prime}$, the red lines surround the surfaces colonized by electroporated cells, the green dotted lines the surfaces colonized by electroporated and non-electroporated TUJ1 ${ }^{+}$MGE neurons, and the blue dotted lines the MGE explants. $\mathbf{G}, \boldsymbol{G}^{\prime}$, At higher magnification, the morphology of control $(\boldsymbol{G})$ and cadherin inactivated MGE neurons $\left(\boldsymbol{G}^{\prime}\right)$. The migration index of electroporated cells $(\boldsymbol{H})$ is the ratio between the areas comprised between the red and blue lines and the green and blue lines. Cadherin inactivated RFP ${ }^{+}$MGE cells colonized a smaller area than control RFP ${ }^{+}$MGE cells around explants $(\boldsymbol{H})$ and extended shorter leading processes $(\boldsymbol{I})$. Histograms show mean $\pm \operatorname{SEM}\left({ }^{* *} p<0.01\right.$, ${ }^{* * *} p<0.001$, Mann-Whitney test in $\boldsymbol{H}$, Student's $t$ test in $\boldsymbol{I}$ ). Scale bars: $\boldsymbol{A}, \boldsymbol{C}, 5 \mu \mathrm{m}, \boldsymbol{F}^{\prime}, 200 \mu \mathrm{m} ; \boldsymbol{G}^{\prime}, 50 \mu \mathrm{m}$. 
A

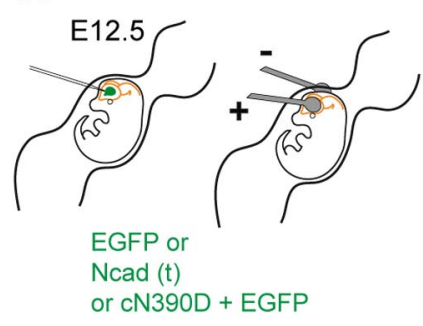

Dissection and observation at $\mathrm{E} 15.5$
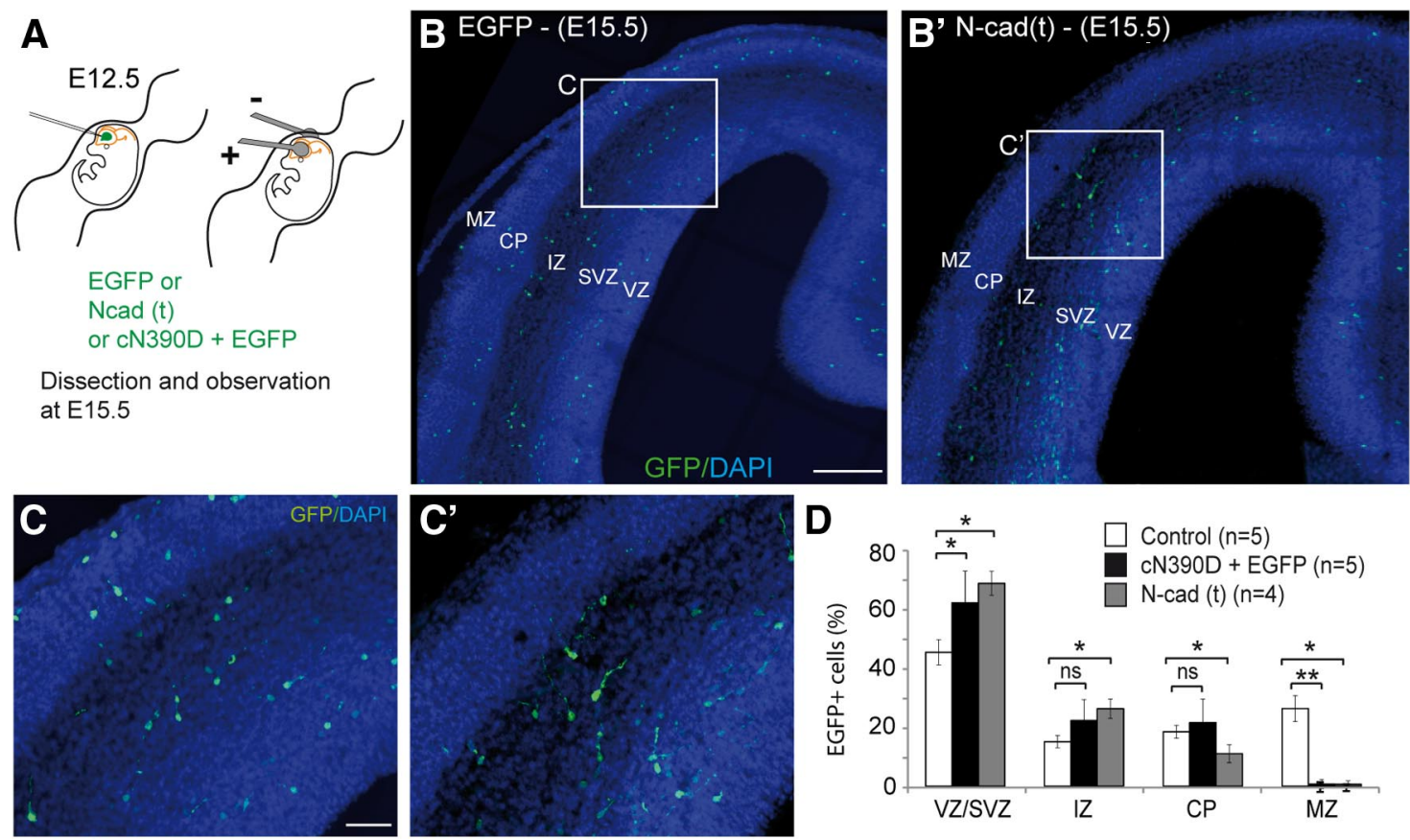

Figure 3. Cadherin inactivation impairs migration to the CP of MGE cells. $\boldsymbol{A}$, Scheme of the experimental design. Constructs were injected in lateral ventricles and in utero electroporation targeted the ventral forebrain. $\boldsymbol{B}, \boldsymbol{B}^{\prime}$, In utero electroporation of dominant-negative $N$-cadherin constructs in wild-type MGE cells $\left(\boldsymbol{B}^{\prime}\right)$ block them in the IZ compared with control ( $\left.\boldsymbol{B}\right)$. $\boldsymbol{C}$ and $\boldsymbol{C}^{\prime}$ are enlarged views of white squares in $\boldsymbol{B}$ and $\boldsymbol{B}^{\prime}$. D, Analysis of GFP ${ }^{+}$cell distribution indicates that most cadherin-invalidated MGE cells remain in the IZ/SVZ, whereas a very small population enters the CP and MZ. Histogram $\boldsymbol{D}$ shows means \pm SEM ( $n=4$ for each condition, Mann-Whitney test, ${ }^{*} p<0.05,{ }^{* *} p<0.01$ ). Scale bars: $\boldsymbol{B}, 100 \mu \mathrm{m} ; \boldsymbol{C}, 40 \mu \mathrm{m}$.

sulting from the loss of the apical junctional complex proteins $\mathrm{N}$-cadherin and $\beta$-catenin. Accordingly, $N$-cadherin $\mathrm{KO}$ neuroepithelial cells built up an aberrant protrusion bulging in the lateral ventricles (Figs. 4, 5 $A^{\prime}, F$ ) and formed rosette-like structures (Fig. $5 F^{\prime \prime}$ ). Some mutant $\mathrm{GFP}^{+}$ cells were found inside the lateral ventricles (Fig. $5 F^{\prime}$, open white arrowheads). Recent reports described an effect of $\mathrm{N}$-cadherin deletion on proliferation of cortical progenitors (Zhang et al., 2010) and an antiapoptotic function of $\mathrm{N}$-cadherin on neuronal cells in vitro (Lelièvre et al., 2012). A mitotic index was calculated as the ratio between the number of cells in mitosis (phospho-histone 3-positive cells) and the total number of cells (DAPI ${ }^{+}$cells). Apoptosis was estimated by counting the number of caspase- $3^{+}$cells over DAPI ${ }^{+}$cells. Cell counting was performed in a region of interest of $10^{4} \mu \mathrm{m}^{2}$, and four animals were analyzed for each condition. Analyses were performed in the $\mathrm{GFP}^{+}$domain of control and $N$-cadherin $\mathrm{CKO}$ animals. Cell counting showed that $N$-cadherin deletion significantly reduced the number of dividing cells (Fig. $5 D, D^{\prime}, E$ ) and significantly increased the number of apoptotic cells $(0.017 \pm 0.0052$ vs $0.025 \pm 0.0086$, mean \pm SEM, $p<0.05)$ at E14.5. The combined reduction of proliferation and enhanced cell death may thus lead to the apparent hypoplasia of $\mathrm{N}$-cadherin ablated regions.

Together, these data indicate that $\mathrm{N}$-cadherin ablation in the territory generating cortical interneurons induces a prominent

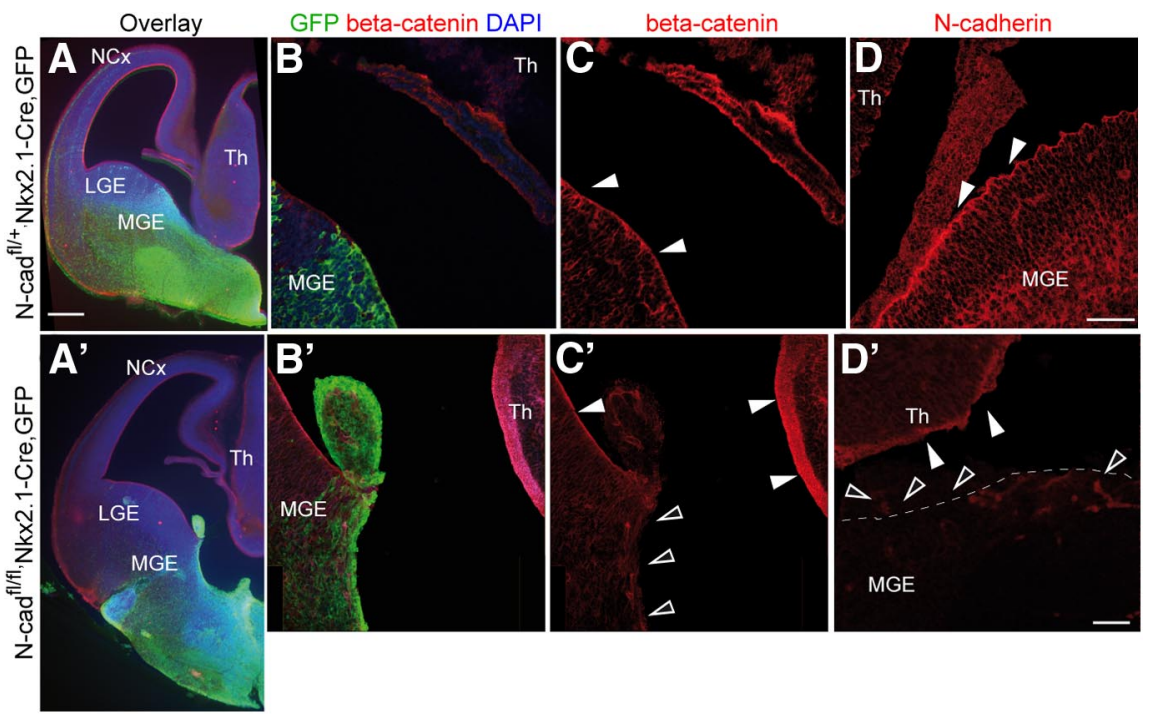

Figure 4. Genetic ablation of N-cadherin in the MGE of mouse embryos. The expression of the apical junctional complex proteins

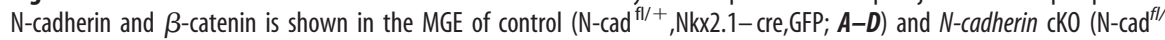
$f$,Nkx2.1-cre,GFP; $\left.\boldsymbol{A}^{\prime}-\boldsymbol{D}^{\prime}\right)$ embryos at E14.5. Coronal sections were immunoreacted with $\mathrm{N}$-cadherin $\left(\boldsymbol{D}, \boldsymbol{D}^{\prime}\right)$ and $\beta$-catenin $(\boldsymbol{B}, \boldsymbol{C}$, $\left.\boldsymbol{B}^{\prime}, \boldsymbol{C}^{\prime}\right)$ antibodies. GFP ${ }^{+}$MGE cells express the $\left(\right.$re recombinase. High-magnification views $\left(\boldsymbol{B}-\boldsymbol{C}^{\prime}\right)$ of frontal sections $\left(\boldsymbol{A}, \boldsymbol{A}^{\prime}\right)$ show the strong expression of $\beta$-catenin at the ventricular side of the basal telencephalon ( $B, C$, white arrowheads), which is suppressed in GFP ${ }^{+}$MGE cells of $\mathrm{N}$-cadherin $\mathrm{CKO}$ embryos $\left(\boldsymbol{B}^{\prime}, \boldsymbol{C}^{\prime}\right.$, open arrowheads). $\boldsymbol{D}, \boldsymbol{D}^{\prime}$, Strong $\mathrm{N}$-cadherin expression in neuronal progenitors and mantle zone of the MGE ( $\boldsymbol{D}$, white arrowheads) is suppressed in the MGE of $\mathrm{N}$-cad ${ }^{f / f t}, N k \times 2.1-\operatorname{cre}$ embryos $\left(\boldsymbol{D}^{\prime}\right.$, open arrowheads). $N\left(x\right.$, Neocortex; Th, thalamus. Scale bars: $A, 250 \mu \mathrm{m} ; \boldsymbol{D}^{\prime} \boldsymbol{D}^{\prime}, 50 \mu \mathrm{m}$.

disorganization of this region and hampers the migration of future cortical interneurons toward the developing neocortex.

MGE cells with $N$-cadherin ablation show abnormal dynamic properties and cell polarity

To determine whether the abnormal distribution of MGE cells in cKO brains resulted from migratory defects, we analyzed in vitro 

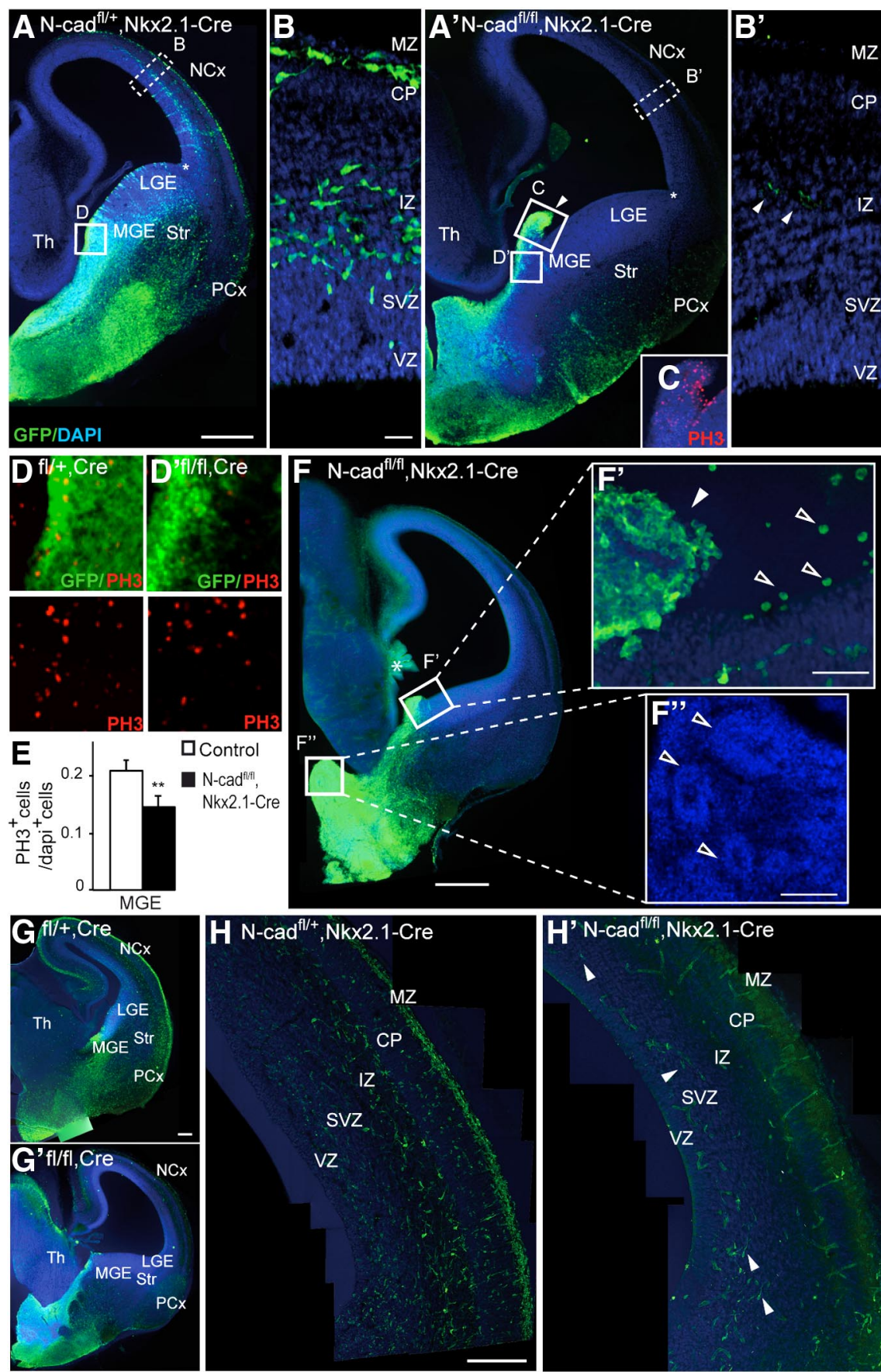

$\square$ Control Nkx21-C
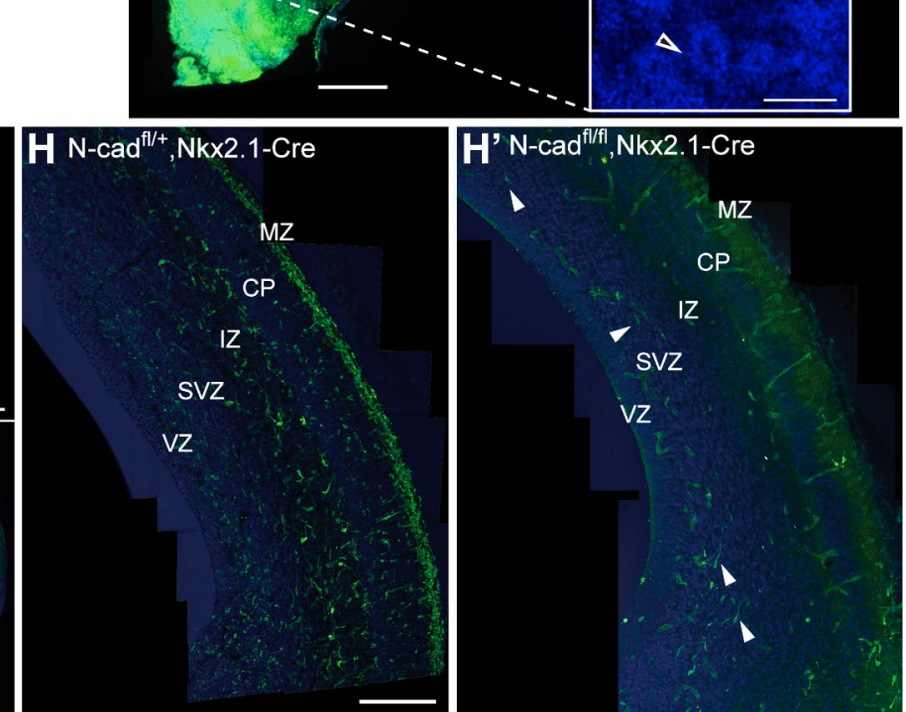

Figure 5. Conditional ablation of N-cadherin in MGE progenitors dramatically impairs MGE morphogenesis and MGE cells distribution in the telencephalon. Coronal sections through the brains of control $\left(\boldsymbol{A}, \boldsymbol{B}, \boldsymbol{D}, \mathbf{G}, \boldsymbol{H}, \mathrm{N}-\mathrm{cad}^{\mathrm{f} /{ }^{+}}, \mathrm{Nkx2.1}\right.$ - $\left.\mathrm{cre}, \mathrm{GFP}\right)$ and $N$-cadherin $\mathrm{CKO}\left(\boldsymbol{A}^{\prime}, \boldsymbol{B}^{\prime}\right.$, $D^{\prime}, F_{-} F^{\prime \prime}, G^{\prime} H^{\prime}, I^{\prime}, \mathrm{N}-$ cad $\left.^{f / / f}, \mathrm{Nkx} 2.1-\mathrm{cre}, \mathrm{GFP}\right)$ transgenic embryos compare the distribution of control and mutant GFP ${ }^{+}$MGE cells in the telencephalon at E14.5 $\left(\boldsymbol{A}-\boldsymbol{F}^{\prime}\right)$ and E16.5 $\left(\mathbf{G}-\boldsymbol{H}^{\prime}\right)$. At E14.5, control MGE cells form two migratory streams in the MZ and IZ/SVZ of the developing cortex $(\boldsymbol{A}, \boldsymbol{B}) . N$-cadherin ablation in MGE hampers MGE cells to leave the subpallium $\left(\boldsymbol{A}^{\prime}\right)$. A few cells reach the ventricular angle (asterisk in $\boldsymbol{A}^{\prime}$ ). Sparse GFP ${ }^{+}$cells can be detected at higher magnification in the cortical IZ $\left(\boldsymbol{B}^{\prime}\right)$. $\boldsymbol{C}-\boldsymbol{E}^{\prime}$, Phospho-histone 3 (PH3, red) antibodies label dividing neuronal progenitors. $N$-cadherin ablated MGE shows a significant reduction of dividing cells $\left(\boldsymbol{D}^{\prime}\right)$ compared with control $(\boldsymbol{D}, \boldsymbol{E})$. N-cadherin ablated $\left(\mathrm{GFP}^{+}\right)$neuroepithelium form aberrant protrusion (white arrowhead in $\boldsymbol{A}^{\prime}, \boldsymbol{F}^{\prime}$ ) and some mutant GFP ${ }^{+}$ cells distribute in the lateral ventricle (open arrowheads in $\boldsymbol{F}^{\prime}$ ). $N$-cadherin ablated neuroepithelial cells in the MGE form neural cell rosettes $\left(\boldsymbol{F}^{\prime}\right)$. $\mathbf{G}-\boldsymbol{H}^{\prime}, \mathbf{N}$-cadherin ablated MGE cells start to reach the developing cortex at E16.5 ( $\boldsymbol{G}^{\prime}$ and enlarged view of cortex in $\left.\boldsymbol{H}^{\prime}\right)$. $\boldsymbol{H}$ is a high-magnification view of the cerebral cortex in $\mathbf{G}$, illustrating the large distribution of control MGE cells in the IZ/SVZ, MZ, and CP at E16.5. NCx, Neocortex; Th, thalamus; Str, striatum; PCX, piriform cortex. Scale bars: $\boldsymbol{A}, \boldsymbol{F}, 300 \mu \mathrm{m} ; \boldsymbol{B}, \boldsymbol{F}^{\prime}, 25 \mu \mathrm{m} ; \boldsymbol{F}^{\prime}, 40 \mu \mathrm{m} ; \boldsymbol{G}, 100 \mu \mathrm{m} ; \boldsymbol{H}, 200 \mu \mathrm{m}$.

the migratory behavior of control $\left(\mathrm{N}-\mathrm{cad}^{\mathrm{fl} /+}, \mathrm{Nkx}-\mathrm{cre}, \mathrm{GFP}\right)$ versus $N$-cadherin $\mathrm{KO}\left(\mathrm{N}-\mathrm{cad}^{f l / f l}, \mathrm{Nkx}\right.$-cre,GFP) MGE cells on a substrate of dissociated wild-type cortical cells. $\mathrm{N}$-cadherin ablated MGE cells were unable to leave their explant of origin and to

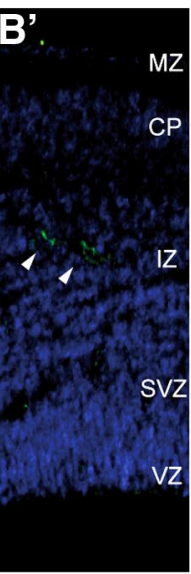

colonize the cortical cell substrate for at least $24 \mathrm{~h}$ after MGE placement on cortical cells (Fig. 6A, Movie 1). After $36 \mathrm{~h}$, a small number of mutant cells migrated out of the explant and covered a much smaller area than that covered by control cells (Fig. 6B, $B^{\prime}$ ). Similarly, $N$-cadherin floxed MGE cells electroporated at E13.5 with Cre recombinase-expression vector migrated in vitro on cortical cells with a migration speed reduced by fourfold compared with control cells (Fig. 6C-E). Cell tracking analysis also showed that $\mathrm{N}$-cadherin-depleted cells displayed meandering trajectories as reflected by a decrease of the direction persistence (Fig. $6 F$ ) and no longer extended stable leading processes (Movie 1, right panel). Altogether, these results show that loss of $\mathrm{N}$-cadherin function in MGE cells perturb their migration by impairing cell polarity and leading process stability.

As observed in vitro, $\mathrm{N}$-cadherin ablated MGE cells located on tangential migratory paths in $\mathrm{cKO}$ embryos (N-cad ${ }^{f / f l}$, Nkx2.1-cre,GFP) manifested major polarity defect. The Golgi apparatus labeled with antibodies against GM130 was aberrantly localized at the rear of the nucleus at a significantly higher frequency in mutant MGE cells compared with the control (Fig. $6 G, G^{\prime}, H$ ). N-cadherin ablated MGE cells exhibited thus polarity defects during their phase of migration and did not normally contribute to the formation of migratory streams.

Postmitotic invalidation of $\mathrm{N}$-cadherin delays MGE cell migration to the cortex and within the $\mathrm{CP}$

To further characterize the contribution of $\mathrm{N}$-cadherin-dependent cell adhesion to the migration of future cortical interneurons toward the developing cortex, we deleted N-cadherin in MGE cells at a postmitotic stage. $N$-cadherin floxed allele mice (Radice et al., 1997) were crossed to Lhx6-Cre, Rosa26R-GFP transgenic mice (Fogarty et al., 2007). In transgenic Lhx6Cre, Rosa26R-GFP embryos, inducible GFP was strongly expressed in MGE cells at E13.5, attesting to efficient genetic ablation of floxed alleles by the Lhx6-Cre transgene (Vidaki et al., 2012). In these animals, the basal telencephalon did not present any obvious morphological defects (Fig. $7 A, A^{\prime}$ ). We analyzed the distribution of $\mathrm{GFP}^{+}$MGE cells with postmitotic ablation of $\mathrm{N}$-cadherin in E13.5, E14.5, and E16.5 embryos (Fig. 7B-E). At all embryonic stages, the density of $\mathrm{GFP}^{+}$MGE cells in the MZ was strongly diminished in $\mathrm{cKO}$ brains $\left(\mathrm{N}-\mathrm{Cad}^{f l / f l}, \mathrm{Lhx} 6-\mathrm{cre}, \mathrm{GFP}\right)$ compared with control brains $\left(\mathrm{N}-\mathrm{Cad}^{\mathrm{H} /+}, \mathrm{Lhx} 6-\mathrm{cre}, \mathrm{GFP}\right)$. Mutant MGE 
A N-cadherin KO MGE explant on cortical cells
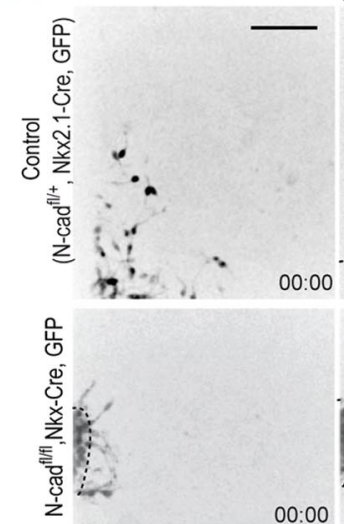

03:00

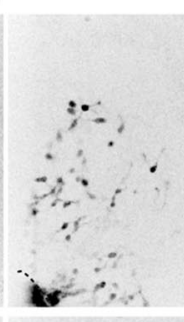

B

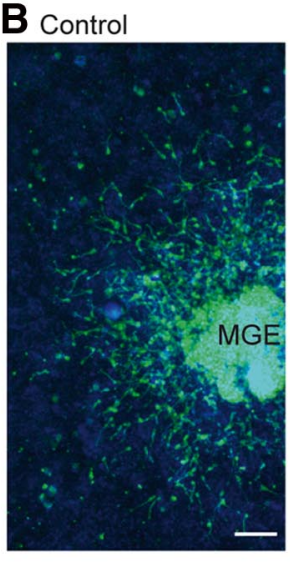

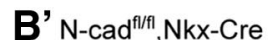

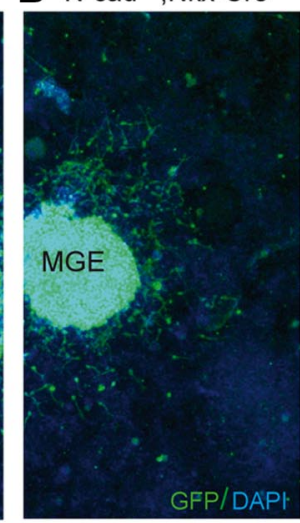

C N-cadherin ablated MGE cells on cortical cells

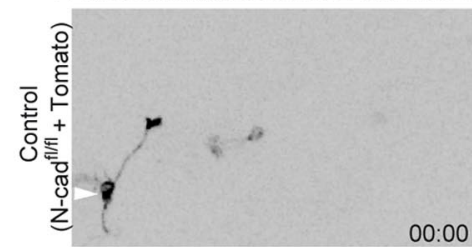

$\infty$
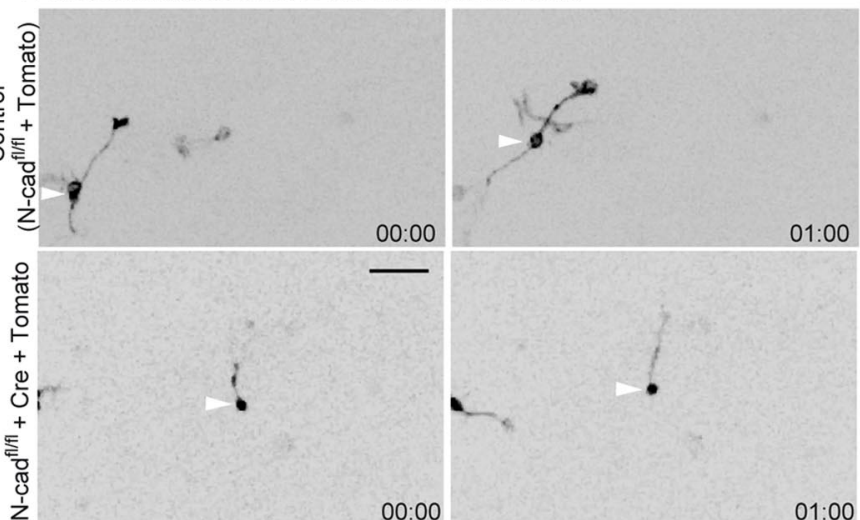

D Mean nuclear migration speed

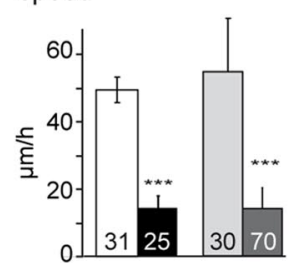

E
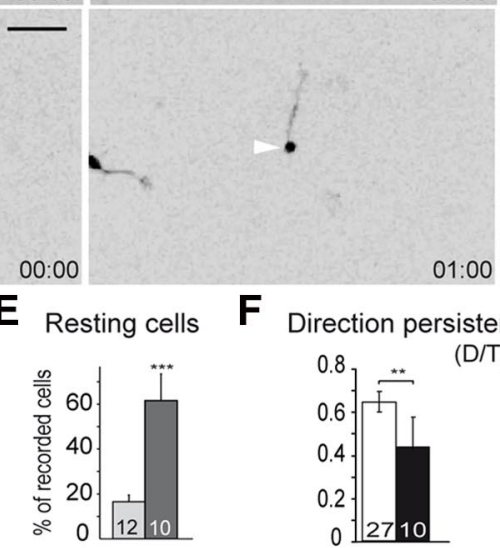

F Direction persistence

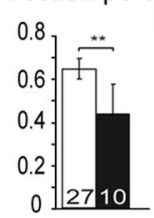

\section{$\square \mathrm{N}-\operatorname{cad}^{\mathrm{fl} / \mathrm{fl}}$, Tomato}

$\mathrm{N}$-cad ${ }^{\text {fl/fil, }}$, Cre + Tomato

\section{$\square \mathrm{N}-\mathrm{cad}^{\mathrm{fl} / \mathrm{+}}, \mathrm{Nkx}-\mathrm{Cre}$}

$(\mathrm{D} / \mathrm{T})$
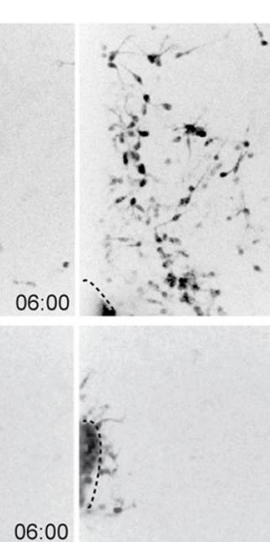

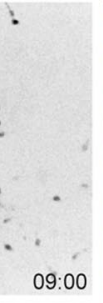

09:00
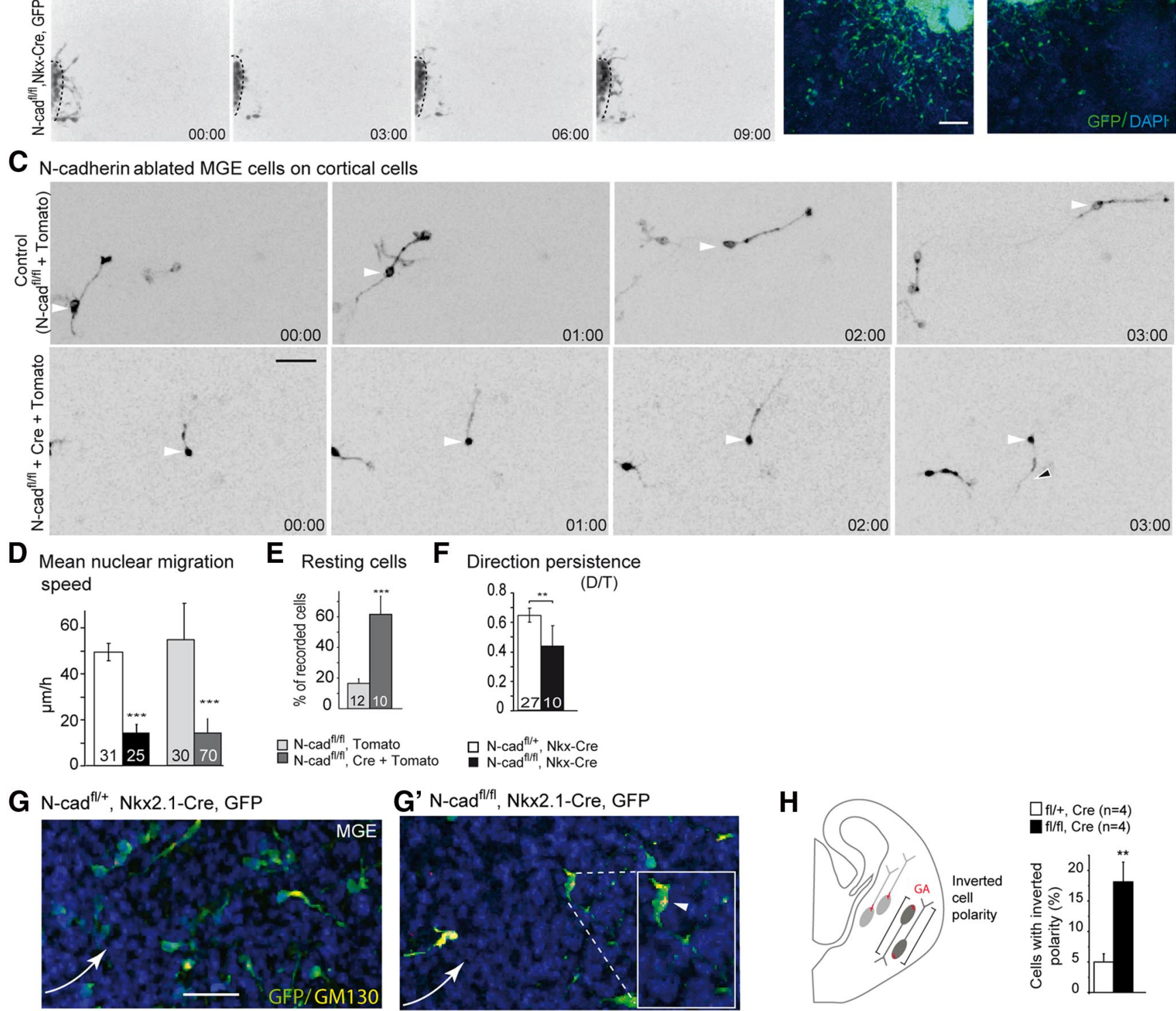

$\mathbf{G}^{\prime} \mathrm{N}-\operatorname{cad}^{\mathrm{fl} / f \mid}, \mathrm{Nkx2}$.1-Cre, GFP

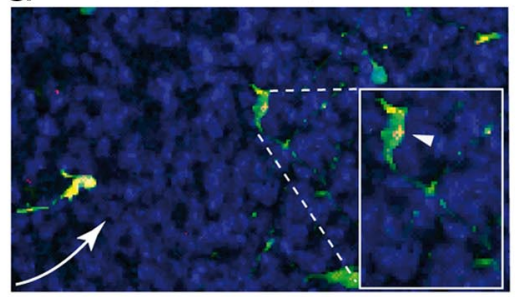

H

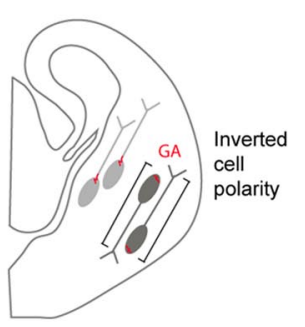

$\square$ fl/ + , Cre $(n=4)$

fl/fl, Cre $(n=4)$

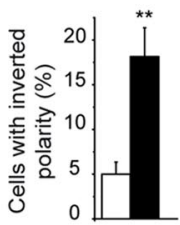

Figure 6. N-cadherin ablation in migrating MGE cells affects migration speed and cell directionality. $\boldsymbol{A}$, Time-lapse imaging of fluorescent MGE cells (inverted LUT) migrating from control (top raw) or $N$-cadherin ablated (bottom raw) E13.5 MGE explants placed in the same cultivation chamber. Recording started $24 \mathrm{~h}$ after placing explants in chamber (time in hours:minutes). Images were taken at 3 min intervals (see also Movie 1), and images at every $3 \mathrm{~h}$ are shown as examples. $\boldsymbol{B}$ and $\boldsymbol{B}^{\prime}$ show the migration of MGE cells around control (B) and $\mathrm{N}$-cadherin mutant $\left(\boldsymbol{B}^{\prime}\right)$ MGE explants at $36 \mathrm{~h}$ of culture. $\boldsymbol{C}$, Time-lapse imaging of MGE cells migrating away from E13.5 $\mathrm{N}$-cadherin ${ }^{\text {fl/fl }}$ MGE explants electroporated with a tomato construct (top raw, control) or coelectroporated with tomato and Cre recombinase constructs (bottom raw). Control MGE cells show dynamic forward translocations of the nucleus (white arrowhead), whereas invalidated MGE cells have no processive movements over $2 \mathrm{~h}$ and invert their polarity (time 3:00, black arrowhead). Time in hours:minutes. $\boldsymbol{D}$, Both $N$-cadherindeleted MGE cells (black bar) and MGE cells with acute $N$-cadherin ablation (dark gray bar) migrate fourfold slower than control cells (white and light gray bars). $\boldsymbol{E}$, $\boldsymbol{F}$, Mutant MGE cells spend more time without moving ( $\boldsymbol{E}$, dark gray bar) and change more frequently their direction as shown by decreased direction persistence $(\boldsymbol{F}$, black bar). Histograms $\boldsymbol{D}-\boldsymbol{F}$ show mean \pm SEM ( ${ }^{* *} p<0.01,{ }^{* * *} p<0.001$, Student's $t$ test). $\mathbf{G}, \boldsymbol{G}^{\prime}$, MGE cell polarity in the basal forebrain of control $(\boldsymbol{G})$ and $N$-cadherin cKO ( $\left.\boldsymbol{G}^{\prime}\right)$ E14.5 embryos was analyzed on coronal sections. The Golgi apparatus (GA) was stained with GM130 antibodies to visualize MGE cell polarity. The curved arrow indicates the direction of the migratory stream in control brains. $\boldsymbol{H}$, Schematic of the criteria chosen for counting cells with inverted polarity. Histogram shows that $N$-cadherin-depleted MGE cells display a significant higher percentage of cells with inverted polarity compared with control (Mann-Whitney test, ${ }^{* *} p<0.01$ ). Scale bars: $\boldsymbol{A}, \boldsymbol{B}, 50 \mu \mathrm{m} ; \boldsymbol{C}, 20 \mu \mathrm{m} ; \boldsymbol{G}, 30 \mu \mathrm{m}$. 


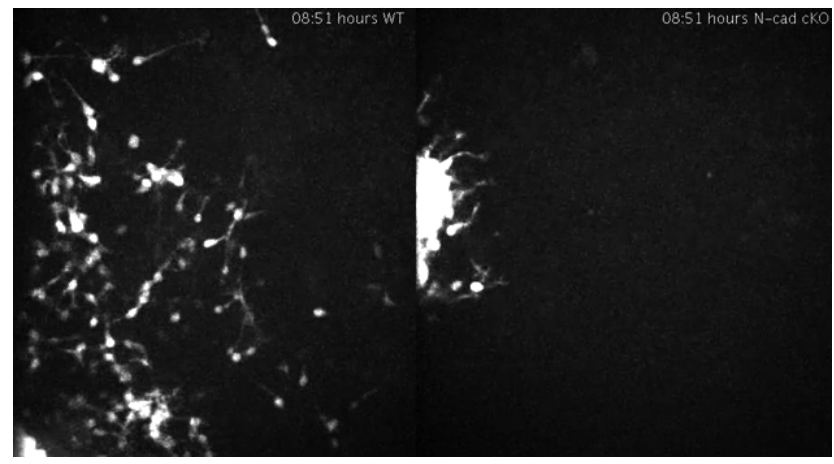

Movie 1. Migration of control and N-cad KO MGE cells on dissociated cortical cells. Time-lapse

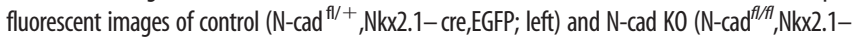
cre,EGFP; right) MGE cells migrating on dissociated cortical cells. Images were acquired at 6 min intervals for $10 \mathrm{~h}$ (10 frames/s). See also Figure $6 \mathrm{~A}$.

cells were two times less numerous than control cells in the deep tangential stream of the lateral cortex at E13.5 (Fig. $7 B, B^{\prime}, C$ ). At E14.5, a small but insignificant difference was still observed. At E16.5, a slightly lower density of $\mathrm{GFP}^{+} \mathrm{MGE}$ cells was observed in the developing cortical wall of cKO embryos (Fig. $7 D, D^{\prime}, E$ ). More interestingly, cell bodies of mutant MGE cells were much less regularly ordered along the radial glial fibers than the cell bodies of control MGE cells (Fig. 7D, $D^{\prime}$ ). Together, these results confirm that $N$-cadherin favors the tangential migration of MGE cells toward the developing cortex and promotes CP invasion along the radial glial cells.

\section{Discussion}

In this study, we investigated the role of the cell adhesion molecule $\mathrm{N}$-cadherin during the tangential migration of future cortical interneurons. Our results show that $\mathrm{N}$-cadherin controls cortical interneuron development at three successive stages. First, $\mathrm{N}$-cadherin ablation in the MGEs strongly disorganized the neuroepithelium. Second, N-cadherin ablated MGE cells hardly exited the MGE and showed decreased motility and a significant defect in maintaining their polarity. Third, N-cadherin ablated MGE cells that reached the dorsal cortex were much less efficient in colonizing the $\mathrm{CP}$, although they finally succeeded at the adult stage, suggesting compensatory mechanisms. Moreover, we demonstrated in vitro that $\mathrm{N}$-cadherin is required for activation of MGE cell motility, for maintenance of cell polarity likely through the regulation of local actomyosin contractile waves and for leading process stabilization. Altogether, these results indicate that $\mathrm{N}$-cadherin is a central player in the migration of future cortical interneurons to the developing cortex.

\section{$\mathrm{N}$-cadherin adhesion stimulates MGE cell motility and is required for the maintenance of their polarization during migration}

The combination of in vivo and in vitro analyses identified at least two main defective processes in cadherin invalidated MGE cells or N-cadherin ablated MGE cells: (1) cell motility and (2) cell polarity. Noteworthy, ablating $\mathrm{N}$-cadherin in MGE cells was as efficient as inactivating classical cadherins to impair MGE cell motility and polarity, showing a preponderant and cellautonomous function of $\mathrm{N}$-cadherin in these cells. N-cadherin ablation drastically decreased the MGE cell migration speed in vitro and significantly delayed their migration in vivo. Conversely, overstimulation of $\mathrm{N}$-cadherin-dependent adhesion on biomimetic substrates increased the migration speed of wild-type
MGE cells. Stimulation of growth cone motility by N-cadherin has been shown previously to sustain neurite elongation (Matsunaga et al., 1988; Bard et al., 2008), and this stimulation has been associated with the anchorage of cadherin molecules to the actomyosin-based motility system (Giannone et al., 2009). However, blocking the function of $\mathrm{N}$-cadherin is not sufficient to completely inhibit cell motility, suggesting either a partial contribution of N-cadherin-dependent actomyosin activity to cell migration or compensatory mechanisms. Accordingly, disruption of $c d h-2$ in zebrafish cerebellar granule cells does not impair cell motility (Rieger et al., 2009), whereas perturbation of cadherin function in tangentially migrating precerebellar neurons induces a delayed migration that affects nucleogenesis in the hindbrain (Taniguchi et al., 2006). Obviously, parallel pathways operate in vivo to control migration speed, and even some $\mathrm{N}$-cadherindepleted MGE cells are still able to reach the CP. It is difficult at this stage to decipher whether it reflects a stochastic behavior of mutant neurons or whether there are some subpopulations in which the lack of $\mathrm{N}$-cadherin can be compensated for by additional pathways.

Our data also show that $\mathrm{N}$-cadherin is required for proper cell polarity maintenance in vivo and in vitro. Polarity defects in $\mathrm{N}$-cadherin invalidated MGE cells are associated with (1) aberrant protrusion of neuroepithelial cells into the ventricles, (2) random walk in vitro and polarity reversal in tangential migratory paths in vivo, and (3) impaired migration along radial glial cells in the developing cortex. The phenotype that we observed in $\mathrm{N}$-cadherin-deleted MGE cells are reminiscent of the loss of directional migration in $\mathrm{N}$-cadherin-depleted early-born neurons during glia-independent somal translocation (Franco et al., 2011) and N-cadherin-depleted multipolar late-born neurons as they enter the CP (Jossin and Cooper, 2011). Surprisingly, overactivation of $\mathrm{N}$-cadherin receptors provided by recombinant $\mathrm{N}$-cadherin substrates stimulated motility but was also associated with a loss of directionality. These results are consistent with current models describing the interplay between polarization and adhesion, in which dynamic formation and removal of adhesion junctions support directional migration in neurons (Kawauchi et al., 2010; for review, see Solecki, 2012). Interestingly, addition of laminin to the N-cadherin coating partially corrected the polarization defects, most likely through the engagement of integrins. This may be attributable to either an instructive signal brought by integrin engagement or a reduction of $\mathrm{N}$-cadherin expression or activity induced by integrin activation. Such interplay between integrins and cadherins has been documented in glial cells and neural tube cells (Fournier-Thibault et al., 2009; Camand et al., 2012). Moreover integrins control the migration of future cortical interneurons. In particular, the interaction between $\alpha 3 \beta 1$ integrin at the surface of MGE cells and the molecular cue netrin-1 is necessary to guide future interneurons from the MGE to the neocortex (Stanco et al., 2009). N-cadherin could cooperate with additional adhesion systems, as recently described between Cajal Retzius cells and radially migrating cortical projection neurons (Gil-Sanz et al., 2013). Accordingly, the protocadherin Celsr 3 is required for the tangential migration of GABAergic neurons in the forebrain (Ying et al., 2009), and gap junctions have been proposed to provide adhesive functions required for switching from tangential to radial migration (Elias et al., 2010).

Although the long-distance migration of future cortical interneurons in extremely complex environments most certainly involves more than one adhesive molecule, it is clear that $\mathrm{N}$-cadherin is constantly present all along the migration path to 

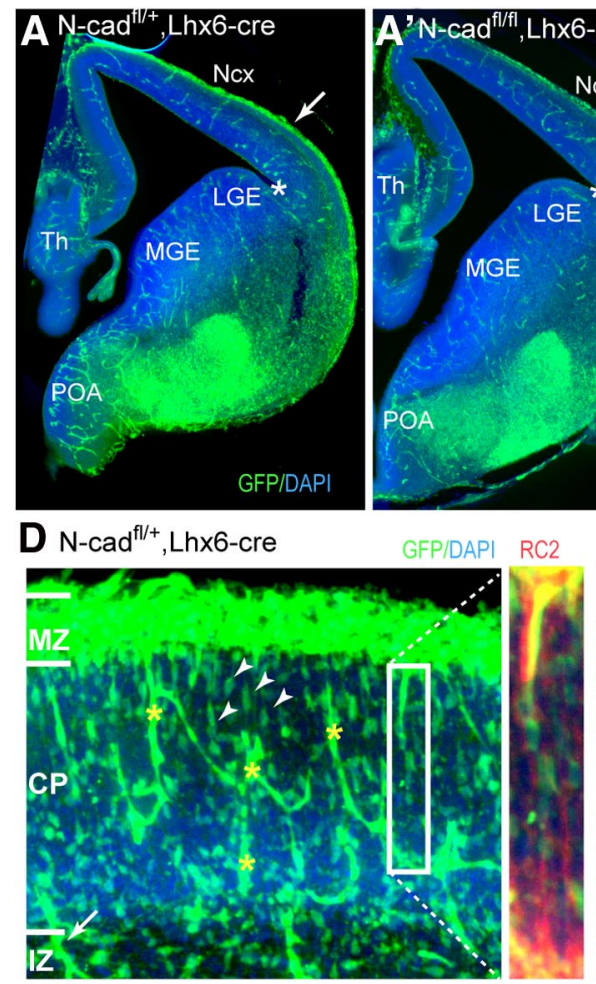
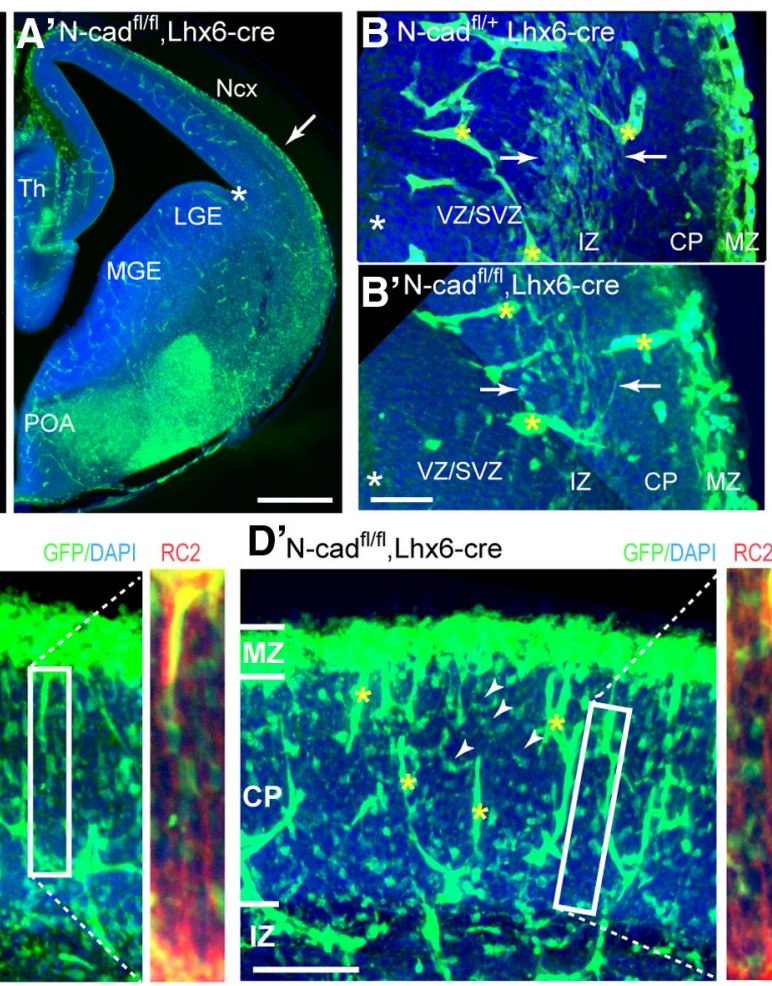

C Number of GFP(+)

neurons in the deep tangential stream

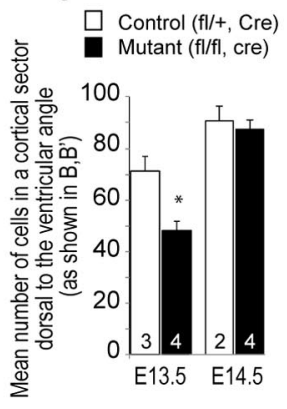

E Density of GFP(+) neurons in cortical plate at E16.5

$\square$ Control (fl/ $/+$, Cre)

Mutant (fl/fl, cre)

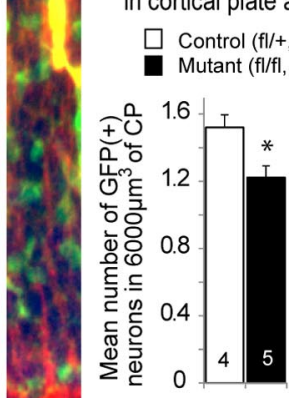

Figure 7. N-cadherin ablation in postmitotic MGE cells delays tangential migration and CP colonization in vivo. Coronal sections through the brains of control (N-cad ${ }^{\mathrm{f} / /+}$, Lhx6cre,GFP; $\boldsymbol{A}, \boldsymbol{B}, \boldsymbol{D})$ and $\mathrm{N}$-cadherin cKO (N-cad $\left.{ }^{f / f f}, \mathrm{Lhx} 6-\mathrm{cre}_{\mathrm{f}} \mathrm{GFP} ; \boldsymbol{A}^{\prime}, \boldsymbol{B}^{\prime}, \mathbf{D}^{\prime}\right)$ transgenic mice illustrate the distribution of control and mutant GFP ${ }^{+}$MGE cells in the telencephalon at E14.5 $\left(\boldsymbol{A}, \boldsymbol{A}^{\prime}\right)$ and in the developing cortex at E13.5 $\left(\boldsymbol{B}, \boldsymbol{B}^{\prime}\right)$ and E16.5 $\left(\boldsymbol{D}, \boldsymbol{D}^{\prime}\right) . \boldsymbol{A}, \boldsymbol{A}^{\prime}$, cKO brains show normal MGE morphogenesis and a decreased number of GFP ${ }^{+}$MGE cells in the MZ of the cortex (white arrows in $\left.\boldsymbol{A}, \boldsymbol{A}^{\prime}\right) \cdot \boldsymbol{B}, \boldsymbol{B}^{\prime}, \boldsymbol{C}$, At E13.5, mutant MGE cells $\left(\boldsymbol{B}^{\prime}\right)$ migrating tangentially in the IZ/SVZ of the lateral cortex (between horizontal white arrows) are less numerous compared with control (B). Cortical sectors used for cell counting in IZ/SVZ are dorsal to the ventricular angle (white asterisk) and $200 \mu \mathrm{m}$ high. Confocal sections were acquired each 1 $\mu \mathrm{m}$ over $13 \mu \mathrm{m}$. Pictures in $\boldsymbol{B}$ and $\boldsymbol{B}^{\prime}$ are Z-projections of cortical sectors used for cell counting. Histogram in $\boldsymbol{C}$ shows that the delay in MGE migration observed at E13.5 in the deep tangential stream is no longer visible at E14.5. $\boldsymbol{D}, \boldsymbol{D}^{\prime}, \boldsymbol{E}$, At E16.5, the density of mutant GFP ${ }^{+}$MGE cells in the MZ is obviously diminished $\left(\boldsymbol{D}^{\prime}\right)$ and cell bodies no longer show the nice radial orientation seen in control cortex ( $\boldsymbol{D}$, white arrowheads). Higher-magnification views of insets in $\boldsymbol{D}$ and $\boldsymbol{D}^{\prime}$ show normal RC2-labeled radial glial cells in cK0 cortex. Counting reveals a smaller density of mutant MGE cells in the (P compared with control (E). Histograms show mean \pm SEM ( ${ }^{*} p<0.05$, Student's $t$ test). Numbers within bars are the number of brains analyzed per genotype. Yellow asterisks indicate GFP-expressing vessels in Lhx6 transgenic mice. NCx, Neocortex; POA, preoptic area; Th, thalamus; Str, striatum; PCX, piriform cortex. Scale bars: $\boldsymbol{A}^{\prime}, 500 \mu \mathrm{m} ; \boldsymbol{B}^{\prime}, 50 \mu \mathrm{m} ; \boldsymbol{D}^{\prime}, 100 \mu \mathrm{m}$.

engage homophilic interactions and to support the tangential migration of future interneurons.

\section{$\mathrm{N}$-cadherin controls polarized migration through centrosome positioning, compartmentalized myosin activation, and leading process stabilization}

During neuronal migration, nuclear translocation toward the leading process occurs after forward movement of the centrosome and Golgi apparatus that form a swelling ahead of the nucleus. The inability of cadherin ablated MGE cells to stabilize cell polarization was correlated to the perinuclear localization of the centrosome/Golgi complex in these cells. The centrosome/Golgi complex was rarely located in the leading process, showing that $\mathrm{N}$-cadherin mediated cell-cell contacts either promote forward migration or stabilize the centrosome/ Golgi complex in the leading process. Recently, it was demonstrated that, during chain migration of zebrafish granule cells, $\mathrm{N}$-cadherin localizes at the leading edge of the migrating neuron in which it stabilizes the centrosome and coordinates cell-cell contacts and cell polarity trough the remodeling of adherent junctions (Rieger et al., 2009). In MGE cells, disruption of $\mathrm{N}$-cadherin function affects both centrosome repositioning ahead of the nucleus and the formation of a cup of myosin IIB at the rear nuclear pole. We observed previously in migrating MGE cells that myosin II concentrates at the rear of the nu- cleus before nucleokinesis, suggesting that actomyosin provided pushing forces to the nucleus, as confirmed recently (Bellion et al., 2005; Martini and Valdeolmillos, 2010; Shinohara et al., 2012). Cadherin engagement has been reported to stimulate Rho GTPases activation, which plays a central role in cell polarization (Noren et al., 2001). However, precise analysis of N-cadherin subcellular distribution and dissection of intracellular signaling activated by $\mathrm{N}$-cadherin engagement will be required to reveal the regulatory pathways involved in the control of cell polarity in migrating interneuron precursors.

Polarity defects in N-cadherin depleted MGE cells may also result from abnormal regulation of microtubule dynamics because a link has been established in various cell types between cadherin-mediated adhesion and microtubules (for review, see Stehbens et al., 2009). In agreement with this hypothesis, the $\mathrm{TUJ} 1^{+}$microtubule bundles that fill the leading process of MGE cells were strongly shortened after cadherin inactivation, and $\mathrm{N}$-cadherin ablation drastically reduced the stability of MGE cell leading process. Whether these cellular responses mainly reflect decreased microtubule stability or involve perturbed cell adhesion remains to be investigated.

In conclusion, $\mathrm{N}$-cadherin is a key component to promote interneuron precursors exit from the MGE and fulfills a central permissive role for their migration. 


\section{$\mathrm{N}$-cadherin deletion in MGE affects both the exit and tangential migration of MGE cells}

Specific deletion of $N$-cadherin in neural precursors disrupts the neuroepithelial integrity with the formation of neural cell rosettes and an intermixing of mature and proliferating cells, as described in other brain regions (Chenn and Walsh, 2002; Lele et al., 2002; Kadowaki et al., 2007). Interestingly, rosettes were also observed in the neuroepithelium of NMIIB KO mice (Ma et al., 2006). Moreover, we observed $\mathrm{GFP}^{+}$cells floating in the ventricles (Fig. $6 C)$. Although we did not demonstrate that these cells originated from the MGE, it is tempting to speculate that significant alteration of neuroepithelial cell adhesion might induce both increased apoptosis in the MGE and aberrant delamination in the ventricle. Disrupted junctions at the ventricular surface might permit cell movements in this region. Conversely, signaling molecules in the CSF would become available to cells normally isolated from the ventricles and could influence their proliferation and/or migration. However, N-cadherin deletion in postmitotic MGE cells confirmed a cell-autonomous role of $\mathrm{N}$-cadherin to control the tangential migration of MGE cells to the cortex and to promote their migration along radial glial cells in the developing CP. In conjunction with the proliferation defect, these results place $\mathrm{N}$-cadherin as a central player in MGE and cortical interneuron development.

\section{References}

Bao J, Ma X, Liu C, Adelstein RS (2007) Replacement of nonmuscle myosin II-B with II-A rescues brain but not cardiac defects in mice. J Biol Chem 282:22102-22111. CrossRef Medline

Bard L, Boscher C, Lambert M, Mège RM, Choquet D, Thoumine O (2008) A molecular clutch between the actin flow and N-cadherin adhesions drives growth cone migration. J Neurosci 28:5879-5890. CrossRef Medline

Baudoin JP, Viou L, Launay PS, Luccardini C, Espeso Gil S, Kiyasova V, Irinopoulou T, Alvarez C, Rio JP, Boudier T, Lechaire JP, Kessaris N, Spassky N, Métin C (2012) Tangentially migrating neurons assemble a primary cilium that promotes their reorientation to the cortical plate. Neuron 76:1108-1122. CrossRef Medline

Bellion A, Baudoin JP, Alvarez C, Bornens M, Métin C (2005) Nucleokinesis in tangentially migrating neurons comprises two alternating phases: forward migration of the Golgi/centrosome associated with centrosome splitting and myosin contraction at the rear. J Neurosci 25:5691-5699. CrossRef Medline

Bixby JL, Zhang R (1990) Purified N-cadherin is a potent substrate for the rapid induction of neurite outgrowth. J Cell Biol 110:1253-1260. CrossRef Medline

Camand E, Peglion F, Osmani N, Sanson M, Etienne-Manneville S (2012) $\mathrm{N}$-cadherin expression level modulates integrin-mediated polarity and strongly impacts on the speed and directionality of glial cell migration. J Cell Sci 125:844-857. CrossRef Medline

Causeret F, Terao M, Jacobs T, Nishimura YV, Yanagawa Y, Obata K, Hoshino M, Nikolic M (2009) The p21-activated kinase is required for neuronal migration in the cerebral cortex. Cereb Cortex 19:861-875. CrossRef Medline

Chenn A, Walsh CA (2002) Regulation of cerebral cortical size by control of cell cycle exit in neural precursors. Science 297:365-369. CrossRef Medline

Elias LAB, Turmaine M, Parnavelas JG, Kriegstein AR (2010) Connexin 43 mediates the tangential to radial migratory switch in ventrally derived cortical interneurons. J Neurosci 30:7072-7077. CrossRef Medline

Fogarty M, Grist M, Gelman D, Marín O, Pachnis V, Kessaris N (2007) Spatial genetic patterning of the embryonic neuroepithelium generates GABAergic interneuron diversity in the adult cortex. J Neurosci 27: 10935-10946. CrossRef Medline

Fournier-Thibault C, Blavet C, Jarov A, Bajanca F, Thorsteinsdóttir S, Duband JL (2009) Sonic hedgehog regulates integrin activity, cadherin contacts, and cell polarity to orchestrate neural tube morphogenesis. J Neurosci 29:12506-12520. CrossRef Medline

Franco SJ, Martinez-Garay I, Gil-Sanz C, Harkins-Perry SR, Müller U (2011)
Reelin regulates cadherin function via Dab1/Rap1 to control neuronal migration and lamination in the neocortex. Neuron 69:482-497. CrossRef Medline

Gänzler-Odenthal SI, Redies C (1998) Blocking N-cadherin function disrupts the epithelial structure of differentiating neural tissue in the embryonic chicken brain. J Neurosci 18:5415-5425. Medline

Giannone G, Mège RM, Thoumine O (2009) Multi-level molecular clutches in motile cell processes. Trends Cell Biol 19:475-486. CrossRef Medline

Gil-Sanz C, Franco SJ, Martinez-Garay I, Espinosa A, Harkins-Perry S, Müller U (2013) Cajal-Retzius cells instruct neuronal migration by coincidence signaling between secreted and contact-dependent guidance cues. Neuron 79:461-477. CrossRef Medline

Hatta K, Takeichi M (1986) Expression of N-cadherin adhesion molecules associated with early morphogenetic events in chick development. Nature 320:447-449. CrossRef Medline

Hirano S, Takeichi M (2012) Cadherins in brain morphogenesis and wiring. Physiol Rev 92:597-634. CrossRef Medline

Jossin Y, Cooper JA (2011) Reelin, Rap1 and N-cadherin orient the migration of multipolar neurons in the developing neocortex. Nat Neurosci 14:697-703. CrossRef Medline

Junghans D, Hack I, Frotscher M, Taylor V, Kemler R (2005) Beta-cateninmediated cell-adhesion is vital for embryonic forebrain development. Dev Dyn 233:528-539. CrossRef Medline

Kadowaki M, Nakamura S, Machon O, Krauss S, Radice GL, Takeichi M (2007) N-cadherin mediates cortical organization in the mouse brain. Dev Biol 304:22-33. CrossRef Medline

Kawauchi T, Sekine K, Shikanai M, Chihama K, Tomita K, Kubo K, Nakajima K, Nabeshima Y, Hoshino M (2010) Rab GTPases-dependent endocytic pathways regulate neuronal migration and maturation through $\mathrm{N}$-cadherin trafficking. Neuron 67:588-602. CrossRef Medline

Kessaris N, Fogarty M, Iannarelli P, Grist M, Wegner M, Richardson WD (2006) Competing waves of oligodendrocytes in the forebrain and postnatal elimination of an embryonic lineage. Nat Neurosci 9:173-179. CrossRef Medline

Lambert M, Padilla F, Mège RM (2000) Immobilized dimers of N-cadherin-Fc chimera mimic cadherin-mediated cell contact formation: contribution of both outside-in and inside-out signals. J Cell Sci 113:2207-2219. Medline

Lele Z, Folchert A, Concha M, Rauch GJ, Geisler R, Rosa F, Wilson SW, Hammerschmidt M, Bally-Cuif L (2002) parachute/n-cadherin is required for morphogenesis and maintained integrity of the zebrafish neural tube. Development 129:3281-3294. Medline

Lelièvre EC, Plestant C, Boscher C, Wolff E, Mège RM, Birbes H (2012) $\mathrm{N}$-cadherin mediates neuronal cell survival through Bim downregulation. PLoS One 7:e33206. CrossRef Medline

Letourneau PC, Shattuck TA, Roche FK, Takeichi M, Lemmon V (1990) Nerve growth cone migration onto Schwann cells involves the calciumdependent adhesion molecule, N-cadherin. Dev Biol 138:430-442. CrossRef Medline

Lien WH, Klezovitch O, Fernandez TE, Delrow J, Vasioukhin V (2006) alphaE-catenin controls cerebral cortical size by regulating the hedgehog signaling pathway. Science 311:1609-1612. CrossRef Medline

Ma X, Kawamoto S, Uribe J, Adelstein RS (2006) Function of the neuronspecific alternatively spliced isoforms of nonmuscle myosin II-B during mouse brain. Mol Biol Cell 17:2138-2149. CrossRef Medline

Marín O, Rubenstein JL (2001) A long, remarkable journey: tangential migration in the telencephalon. Nat Rev Neurosci 2:780-790. CrossRef Medline

Marín O, Valiente M, Ge X, Tsai LH (2010) Guiding neuronal cell migrations. Cold Spring Harb Perspect Biol 2:a001834. CrossRef Medline

Martini FJ, Valdeolmillos M (2010) Actomyosin contraction at the cell rear drives nuclear translocation in migrating cortical interneurons. J Neurosci 30:8660-8670. CrossRef Medline

Matsunaga M, Hatta K, Nagafuchi A, Takeichi M (1988) Guidance of optic nerve fibres by N-cadherin adhesion molecules. Nature 334:62-64. CrossRef Medline

Mège RM, Gavard J, Lambert M (2006) Regulation of cell-cell junctions by the cytoskeleton. Curr Opin Cell Biol 18:541-548. CrossRef Medline

Miyatani S, Shimamura K, Hatta M, Nagafuchi A, Nose A, Matsunaga M, Hatta K, Takeichi M (1989) Neural cadherin: role in selective cell-cell adhesion. Science 245:631-635. CrossRef Medline

Noren NK, Niessen CM, Gumbiner BM, Burridge K (2001) Cadherin en- 
gagement regulates Rho family GTPases. J Biol Chem 276:33305-33308. CrossRef Medline

Radice GL, Rayburn H, Matsunami H, Knudsen KA, Takeichi M, Hynes RO (1997) Developmental defects in mouse embryos lacking N-cadherin. Dev Biol 181:64-78. CrossRef Medline

Redies C, Takeichi M (1993) Expression of N-cadherin mRNA during development of the mouse brain. Dev Dyn 197:26-39. CrossRef Medline

Redies C, Takeichi M (1996) Cadherins in the developing central nervous system: an adhesive code for segmental and functional subdivisions. Dev Biol 180:413-423. CrossRef Medline

Rieger S, Senghaas N, Walch A, Köster RW (2009) Cadherin-2 controls directional chain migration of cerebellar granule neurons. PLoS Biol 7:e1000240. CrossRef Medline

Riehl R, Johnson K, Bradley R, Grunwald GB, Cornel E, Lilienbaum A, Holt CE (1996) Cadherin function is required for axon outgrowth in retinal ganglion cells in vivo. Neuron 17:837-848. CrossRef Medline

Schaar BT, McConnell SK (2005) Cytoskeletal coordination during neuronal migration. Proc Natl Acad Sci U S A 102:13652-13657. CrossRef Medline

Shinohara R, Thumkeo D, Kamijo H, Kaneko N, Sawamoto K, Watanabe K, Takebayashi H, Kiyonari H, Ishizaki T, Furuyashiki T, Narumiya S (2012) A role for mDia, a Rho-regulated actin nucleator, in tangential migration of interneuron precursors. Nat Neurosci 15:373-380, S1-S2. CrossRef Medline

Solecki DJ (2012) Sticky situations: recent advances in control of cell adhesion during neuronal migration. Curr Opin Neurobiol 22:791-798. CrossRef Medline

Stanco A, Szekeres C, Patel N, Rao S, Campbell K, Kreidberg JA, Polleux F, Anton ES (2009) Netrin-1-alpha3betal integrin interactions regulate the migration of interneurons through the cortical marginal zone. Proc Natl Acad Sci U S A 106:7595-7600. CrossRef Medline

Stehbens SJ, Akhmanova A, Yap AS (2009) Microtubules and cadherins: a neglected partnership. Front Biosci (Landmark Ed) 14:3159-3167. CrossRef Medline

Tanaka D, Nakaya Y, Yanagawa Y, Obata K, Murakami F (2003) Multimodal tangential migration of neocortical GABAergic neurons independent of GPI-anchored proteins. Development 130:5803-5813. CrossRef Medline

Taniguchi H, Kawauchi D, Nishida K, Murakami F (2006) Classic cadherins regulate tangential migration of precerebellar neurons in the caudal hindbrain. Development 133:1923-1931. CrossRef Medline

Tsai JW, Bremner KH, Vallee RB (2007) Dual subcellular roles for LIS1 and dynein in radial neuronal migration in live brain tissue. Nat Neurosci 10:970-979. CrossRef Medline

Vidaki M, Tivodar S, Doulgeraki K, Tybulewicz V, Kessaris N, Pachnis V, Karagogeos D (2012) Rac1-dependent cell cycle exit of MGE precursors and GABAergic interneuron migration to the cortex. Cereb Cortex 22: 680-692. CrossRef Medline

Yanagida M, Miyoshi R, Toyokuni R, Zhu Y, Murakami F (2012) Dynamics of the leading process, nucleus, and Golgi apparatus of migrating cortical interneurons in living mouse embryos. Proc Natl Acad Sci U S A 109: 16737-16742. CrossRef Medline

Ying G, Wu S, Hou R, Huang W, Capecchi MR, Wu Q (2009) The protocadherin gene Celsr3 is required for interneuron migration in the mouse forebrain. Mol Cell Biol 29:3045-3061. CrossRef Medline

Zhang J, Woodhead GJ, Swaminathan SK, Noles SR, McQuinn ER, Pisarek AJ, Stocker AM, Mutch CA, Funatsu N, Chenn A (2010) Cortical neural precursors inhibit their own differentiation via $\mathrm{N}$-cadherin maintenance of beta-catenin signaling. Dev Cell 18:472-479. CrossRef Medline 